Research Article

\title{
Experimental Research on Parameters of a Late-Model Hydraulic-Electromotor Hybrid Pumping Unit
}

\author{
Chunyou Zhang, ${ }^{1,2}$ Liang Wang $\mathbb{D},{ }^{1}$ Hong $\mathrm{Li}^{1}$, and Lihua Wang $\mathbb{D}^{2}$ \\ ${ }^{1}$ School of Automation Science and Electrical Engineering, Beihang University, Beijing 100191, China \\ ${ }^{2}$ College of Mechanical Engineering, Inner Mongolia University for Nationalities, Tongliao, Inner Mongolia 028000, China
}

Correspondence should be addressed to Liang Wang; wangliang@buaa.edu.cn and Lihua Wang; wanglihua7967@163.com

Received 5 November 2019; Accepted 9 March 2020; Published 15 May 2020

Academic Editor: Efstratios Tzirtzilakis

Copyright ( $) 2020$ Chunyou Zhang et al. This is an open access article distributed under the Creative Commons Attribution License, which permits unrestricted use, distribution, and reproduction in any medium, provided the original work is properly cited.

\begin{abstract}
Beam pumping unit is widely applied in the oilfield area. However, the falling process of the pumping unit horsehead causes large-amplitude variations of the motor torque and greatly reduces the efficiency of the system. This paper proposes a late-model hydraulic-electromotor hybrid system which can realize energy recovery and assist electromotor work. The hybrid system can improve the matching characteristics between the electromotor and the pumping unit. A mathematical model is built and verified by experiment studies. According to the experimental and simulation results, it can be concluded that energy recovery function of the designed hydraulic-electromotor hybrid system is demonstrated to be effective, and the electromotor can keep the output power stable. As the efficiency of the hybrid power system affects the energy-saving effect, this paper establishes the efficiency model of the system and studies the key parameters affecting the efficiency of the system through experiments and simulation. The key parameters include the minimum displacement ratio of the pump and hydraulic motor, working pressure, and transmission ratio. This paper proposes a parameter optimization design method of the hydraulic-electromotor hybrid system. Under the optimal parameter combination, the hydraulicelectromotor hybrid system efficiency can reach $92 \%$, and the electric power transmission efficiency of the system can be raised to $75 \%$.
\end{abstract}

\section{Introduction}

At present, $85 \%$ of the lifting system used in the oilfield production is a rod pumping system, which is composed of a pumping unit, pumping rod, and electromotor $[1,2]$. Beam pumping unit has gained wide application on oil extraction in the oilfield around the world for the advantage of simple structure, high reliability, and easy maintenance [3]. However, the unbalanced structure of the beam pumping unit leads to wild fluctuation of the load torque on the transmission shaft and even can cause a negative torsional moment of the drive motor. This makes the motor in a generating state [4], and it will result in electronic energy loss or even electric network pollution. In order to meet the starting requirements of the pumping unit, the motor has high installed power. For these reasons, the motor often runs under light load with low efficiency. The average operating efficiency of the motor is approximately $40 \%$, and the efficiency of the mechanical oil production system is between $12 \%$ and $23 \%$ [5]. How to improve motor efficiency and achieve load matching is the key to oilfield energy saving.

Researchers have improved the structure of the beam pumping unit based on pumping principle. Feng et al. [6] has proved the effectiveness of the new structure of phased pumping unit. Fu et al. [7] has designed a double horsehead pumping unit, and his team has verified the energy-saving effect based on simulation study. However, structural changes increase the complexity and cost of the mechanical system. Therefore, a number of scientists have deeply studied the dynamic pumping model in order to theoretically implement energy saving. Feng et al. [8] accurately built the mathematical model of the load motor based on the dynamic 
changing of the pumping load, and they realized the system power matching which can improve the motor efficiency. The energy analyzing model and 3D dynamic model have also been built $[9,10]$. In addition, the motor operating in generation mode will cause huge waste of energy. In order to avoid the motor being in power generation mode, Yingli et al. [11] proposed an intermittent power supply control method which can save the electric energy. Zhao et al. [12] have studied the accurate method for determining the interruption time of intermittent power supply technology. However, the load fluctuation still exists despite the optimization of the structure and control of the pumping unit system.

The key problem of energy saving of beam pumping machine is to realize energy regulation and rational application by adopting a proper structure so as to improve motor efficiency and realize energy saving. Numerous studies have shown that the mechanical balance structure could not realize the dynamic adjustment of electric power effectively, and the motor power fluctuation still exists. But the hydraulic system can meet the dynamic power regulation and realize the matching of motor and pumping unit. The commonly used hydraulic hybrid system is mainly composed of hydraulic accumulator and hydraulic secondary components-pump/motor. Hydraulic secondary components can realize energy recovery and assist prime mover work, and it can be used in hybrid vehicles and hybrid heavyduty crane to achieve energy saving [13-16]. Liang et al. [17] studied the energy saving of pumping unit based on hydraulic pump/motor, and the simulation results show that the hydraulic regulation scheme can reduce load fluctuation and improve electromotor efficiency. But the hydraulic secondary components have shortcomings such as complex structure, high price, single variety, and low efficiency [18]. Therefore, it cannot suitable for oilfield application.

Based on the above analysis, it can be obtained that the hydraulic system can realize energy saving and this scheme is more effective compared with others. So, his paper proposes a late-model hydraulic-electromotor hybrid system which can meet energy saving. The new system can replace the hydraulic pump/motor by connecting the pump and hydraulic motor with a torque coupling structure. It can realize the function of energy recovery and auxiliary electromotor drive. Moreover, the lower cost of pump and hydraulic motor is more conducive for the oilfield applications. The new hydraulic-electromotor hybrid system is very significant for energy saving in oilfield.

In this paper, mathematic model of the hydraulicelectromotor hybrid system is established. In order to research the performance of the hybrid system, the experiment table is built. By experiment and simulation, the availability of the hydraulic-electromotor hybrid system is verified. According to the experimental results, the energy loss of the hybrid system will affect energy saving effect. If the efficiency of the hybrid system is lower, it will not save energy. Therefore, this paper establishes the efficiency model of the hybrid system and studies the key parameters that affect the efficiency of the hybrid system. Finally, the parameter optimization design method of the hybrid system is established.

\section{Configuration of Hydraulic-Electromotor Hybrid Pumping Unit}

Configuration model of the hydraulic-electromotor hybrid beam pumping unit is proposed as shown in Figure 1, and the simplified model of beam pumping unit is shown in the right part of Figure 1. It consists of two parts: the down hole and the ground. The down hole parts are mainly sucker pump, oil pipe, and sucker rod. The sucker rod connects the down hole to the surface and drives the plungers move up and down to realize the process of oil absorption and discharge. They are all highly efficient in the process of work. The ground part mainly includes suspension point, horsehead, beam, Link rod, balance weight, crank, reducer, belt, and pulley. These parts mainly realize the energy transfer with high transmission efficiency. Throughout the whole power transmission chain of pumping unit, only the motor has low operating efficiency.

The new hydraulic-electromotor energy regulating system is shown in the left part of Figure 1, and it mainly contains torque coupling gearbox, reducer, a variable-displacement pump, a variable-displacement motor, and an accumulator. Torque coupling gear group can realize power shunt and confluence, and it meets energy regulation need. Hydraulic motor, hydraulic pump, and electromotor are connected by torque coupling gear group. When the hydraulic motor displacement is more than the pump, the hydraulic system is in "hydraulic motor mode" and outputs energy. When the hydraulic motor displacement is less than the pump, the hydraulic system is in "hydraulic pump mode" and stores energy.

The beam pumping unit is only driven by high-power electromotor. During the up and down strokes of one oil pumping period, value of the torque on load shaft changes greatly. The new hydraulic-electromotor energy regulating system is added between the electromotor and the pumping unit, and it can assist the electromotor to work together and achieve energy recovery. When the sucker rod falls, the electromotor usually operates under light load. At this time, the displacement of the pump is adjusted to be larger than the hydraulic motor, which can increase the load rate of the electromotor, store electric energy into the hydraulic system, and stabilize the output power of the electromotor. Hydraulic system recycles the gravity potential energy of the horsehead and the sucker rod, avoiding the power generation mode of the electromotor. When the sucker rod is lifted, the displacement of the hydraulic motor is larger than that of the pump, the stored pressure energy is released and provides kinetic energy to the load shaft together with the electromotor. The new hydraulic-electromotor hybrid system can realize the function of "peak cutting and valley filling" and the power output of the motor is stable when the load power changes. So, the system can improve the efficiency of the motor and realize the load matching. 


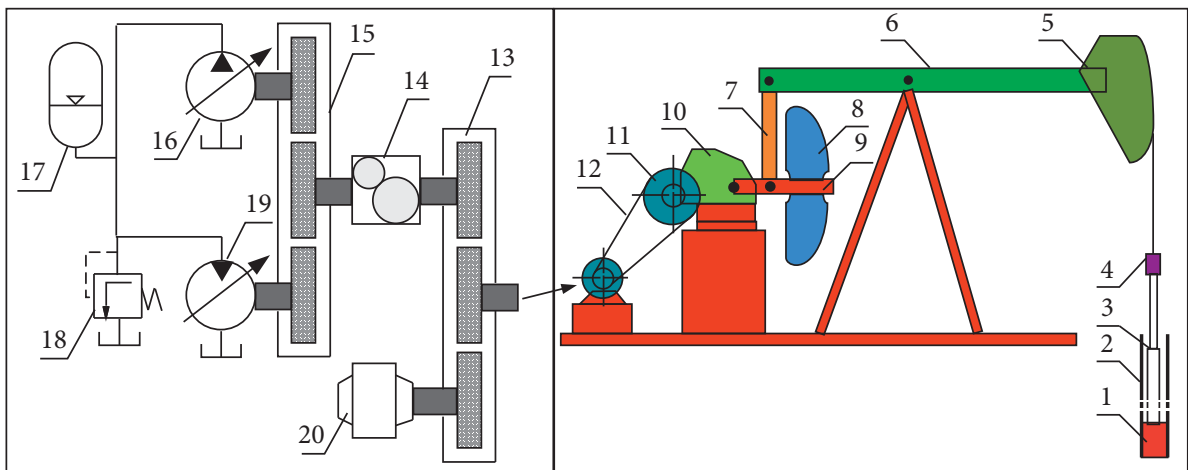

FIGURE 1: The structure of the hydraulic-electromotor hybrid beam pumping unit. 1. Sucker pump; 2. Oil pipe; 3. Sucker rod; 4. Suspension point; 5. Horsehead; 6. Beam; 7. Link rod; 8. Balance weight; 9. Crank; 10. Reducer (1); 11. Pulley; 12. Belt; 13. Torque coupling gearbox (1); 14. Reduce (2); 15. Torque coupling gearbox (2); 16.Variable-displacement pump; 17.Accumulator; 18. Relief valve; 19. Variable-displacement motor; 20. Electromotor.

\section{Modeling Demonstration of the Hydraulic- Electromotor Hybrid System}

Mathematical model of the hydraulic-electromotor hybrid system has been analyzed and demonstrated according to its working principle. Moreover, in order to simplify the research problem, it is assumed that the hydraulic pipeline should be as short as possible, and the compressibility of the oil should be left out. In other words, the influence of the hydraulic pipeline and the internal volume of the pump or motor of the hydraulic system should be ignored. The influence of the low-pressure side pipeline pressure on the system should not be considered, and the low-pressure side pipeline pressure should be regarded as zero $[19,20]$. Because the leakage flows through a small gap, the leakage of hydraulic pump and hydraulic motor can be considered laminar flow, and the pressure inside the shell is atmospheric pressure. The leakage from the low-pressure side into the shell is ignored. The pressure of the hydraulic system is uniform, and viscosity of liquid density and dynamic are constant.

3.1. Equations of the Variable-Displacement Pump. The displacement of the variable pump can be changed by changing the swash plate angle of the pump. There is flow loss when the pump is working. In order to simplify the research problem, the liquid leakage of the pump can be seen as laminar flow. The displacement equation and the laminar leakage flow equation are as follows:

$$
\begin{aligned}
D_{P} & =D_{p \max } \cdot \beta_{p}, \\
\Delta q_{p} & =C_{p s} \cdot D_{p \max } \cdot \frac{p_{h}}{\mu} .
\end{aligned}
$$

So, the flow equation of the pump is as follows:

$$
q_{p}=\frac{1}{60} D_{p} \cdot n_{p}-\Delta q_{p}
$$

Due to the existence of mechanical friction and viscous friction inside the pump, a certain torque loss is caused. The friction loss torque of the pump is as follows:

$$
\Delta T_{p}=\frac{D_{p \max }}{2 \pi} \cdot\left(C_{p v} \cdot \frac{\mu}{60} \cdot n_{p}+C_{p f} \cdot p_{h}\right) .
$$

Consider the inertia torque loss, the drive torque equation of pump can be seen as follows:

$$
T_{p}=\frac{p_{h} \cdot D_{p}}{2 \pi}+\Delta T_{p}+J_{p} \cdot \alpha_{p} .
$$

3.2. Equation of the Variable-Displacement Hydraulic Motor. Because hydraulic motor and pump are reversible in principle, they are similar in structure. Hydraulic motor and pump have the same basic structural elements. Therefore, the hydraulic motor and pump have the same modeling process. The displacement equation of hydraulic motor is as follows:

$$
D_{m}=D_{m \max } \cdot \beta_{m} .
$$

Hydraulic motor also has leakage phenomenon, and its flow loss equation is as follows:

$$
\Delta q_{m}=C_{m s} \cdot D_{m \max } \cdot \frac{p_{h}}{\mu} .
$$

The flow equation of hydraulic motor is as follows:

$$
q_{m}=D_{m} \cdot n_{m}+\Delta q_{m} .
$$
follows:

The friction loss torque of hydraulic motor can be seen as

$$
\Delta T_{m}=\frac{D_{m \max }}{2 \pi} \cdot\left(C_{m v} \cdot \frac{\mu}{60} \cdot n_{m}+C_{m f} \cdot p_{h}\right) .
$$

Torque equation of hydraulic motor is as follows:

$$
T_{m}=\frac{p_{h} \cdot D_{m}}{2 \pi}-\Delta T_{m}-J_{m} \cdot \alpha_{m}
$$


3.3. Flow Equation of the Hydraulic Accumulator. As is analyzed above, the hydraulic accumulator is used to store and reuse the energy during the down stroke process of the beam pumping unit. According to Boyle's law, the volume of an ideal gas is inversely proportional to the pressure of the gas at constant temperature, and then we can get that

$$
P_{0} \cdot V_{0}^{r}=P_{a} \cdot V_{a}^{r} .
$$

Equation (11) takes the derivative with respect to time; we can get the equation as follows:

$$
\frac{\mathrm{d} p_{a}}{\mathrm{~d} t}=-\frac{r \cdot P_{a}}{V_{a}} \cdot \frac{\mathrm{d} V_{a}}{\mathrm{~d} t} .
$$

Because the inlet flow of the accumulator is equal to the volume change of the internal gas, the flow of the accumulator and the volume of gas can be expressed as follows [21]:

$$
\begin{aligned}
q_{a} & =-\frac{\mathrm{d} V_{a}}{\mathrm{~d} t}, \\
V_{a} & =\frac{p_{0}^{(1 / r)} \cdot V_{0}}{P_{a}^{(1 / r)}} .
\end{aligned}
$$

If the influence of the interface pipeline on the accumulator is not considered, when the gas in the accumulator is compressed, its internal gas pressure $P_{a}$ is equal to that of the external pipeline pressure $P_{h}$. Then the flow equation of the accumulator can be expressed as follows:

$$
q_{a}=\frac{p_{0}^{(1 / r)} \cdot V_{0}}{r \cdot p_{a}^{(r+1 / r)}} \cdot \frac{\mathrm{d} p_{a}}{\mathrm{~d} t}=\frac{p_{0}^{(1 / r)} \cdot V_{0}}{r \cdot p_{h}^{(r+1 / r)}} \cdot \frac{\mathrm{d} p_{h}}{\mathrm{~d} t} .
$$

3.4. System Torque Equation and Flow Equation. The mechanical coupling gear groups can realize shunt and confluence of the torque, and then energy regulation of the hydraulic system can be realized through the torque coupled gear train. Torque coupling means in the coupling process, output torque of two power sources is independent from each other, while the output speed must be equal before the dynamic coupling. The final synthetic torque is the superposition of output torque of two power sources. The structure of the coupling gears is as shown in Figure 2.

The relationship between the rotational speed and the torque of the coupling drive shaft is as follows:

$$
\begin{aligned}
& \vec{n}_{1}=\vec{n}_{2}=\vec{n}_{3}=\vec{n}_{4}, \\
& \vec{T}_{1}+\vec{T}_{2}+\vec{T}_{3}=\vec{T}_{4},
\end{aligned}
$$

where $\vec{n}_{1}, \vec{n}_{2}, \vec{n}_{3}$ and $\vec{n}_{4}$ are the revolving speed of the output shafts of the gear coupling group and $\vec{T}_{1}, \vec{T}_{2}, \vec{T}_{3}$ and $\vec{T}_{4}$ are the values of the torques of the shafts.

Crank speed of pumping unit is $n_{L}$ and torque of the crank shaft is $T_{L}$. Electromotor speed is expressed as $n_{e}$ and output toque is expressed as $T_{e}$. The total transmission

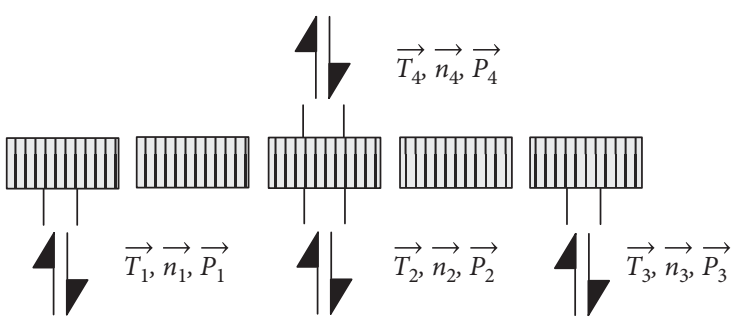

FigURE 2: Structure of the coupling gear groups.

of the reducer and the belt pulley is $i$, and the reducer (2) transmission ratio is $i_{1}$. According to torque coupling requirements, hydraulic motor and pump have the same speed value. Speed relation and torque equation are as follow:

$$
\begin{aligned}
n_{p} & =n_{m}=n_{e} \cdot i_{1}=n_{L} \cdot i \cdot i_{1}, \\
\left(T_{m}-T_{p}\right) \cdot i_{1}+T_{e}-\Delta T & =\frac{T_{L}}{i} .
\end{aligned}
$$

According to the hydraulic-electromotor hybrid system, the flow equation of the system is expressed as follows:

$$
q_{p}-q_{a}=q_{m}
$$

3.5. System Efficiency Equations. Although the efficiency of the motor can be improved through the hydraulic-electromotor hybrid system, if the new structure is low efficiency, the energy-saving characteristics of the hybrid system will be affected or even not energy-saving. Therefore, it is very important to study the efficiency of the new structure. Due to the high efficiency of mechanical transmission itself, the gear efficiency can reach $98 \%$ and the bearing efficiency can reach $99 \%$. In order to simplify the model, the energy loss of gear transmission is ignored. Therefore, the efficiency of hydraulic system is the main influence of energy saving. Before establishing the system efficiency model, this paper makes the following assumptions: (1) Length of pipelines in the hydraulic system is ignored. (2) When the motor drives the pumping unit, the rotation speed is usually considered to be constant, so the inertia torque loss of the system is not considered. (3) Temperature of the hydraulic oil is considered to be approximately constant. (4) Hydraulic accumulator can be considered as an adiabatic process because of its fast rate of filling and discharging in the cycle of the pumping unit. The efficiency model of hydraulic-electromotor hybrid system is established as follows:

$$
\eta=1-\frac{P_{p-\text { loss }}-P_{m-\text { loss }}}{P_{e}} .
$$

According to the flow loss equation and torque loss equation, $P_{p \text {-loss }}$ and $P_{m \text {-loss }}$ is obtained as follows: 


$$
\begin{aligned}
P_{p-\text { loss }}= & \frac{C_{p s}}{\mu} \cdot D_{p \max } \cdot p_{h}^{2}+\frac{\mu \cdot C_{p v}}{3600} \cdot D_{p \max } \\
& \cdot n_{p}^{2}+\frac{C_{p f}}{60} \cdot n_{p} \cdot D_{p \max } \cdot p_{h}, \\
P_{m-\text { loss }}= & \frac{C_{m s}}{\mu} \cdot D_{m \max } \cdot p_{h}^{2}+\frac{\mu \cdot C_{m v}}{3600} \cdot D_{m \max } \\
& \cdot n_{m}^{2}+\frac{C_{m f}}{60} \cdot n_{m} \cdot D_{m \max } \cdot p_{h} .
\end{aligned}
$$

Finally, the hydraulic-electromotor hybrid system efficiency equation is obtained as follows:

$$
\begin{aligned}
\eta= & 1-\frac{9.554}{T_{e} \cdot n_{e}} \cdot\left(\frac{C_{p s}}{\mu} \cdot D_{p \max } \cdot p_{h}^{2}+\frac{\mu \cdot C_{p v} \cdot D_{p \max } \cdot n_{p}^{2}}{3600}\right. \\
& +\frac{C_{p f} \cdot n_{p} \cdot D_{p \max } \cdot p_{h}}{60}+\frac{C_{m s}}{\mu} \cdot D_{m \max } \cdot p_{h}^{2} \\
& \left.+\frac{\mu \cdot C_{m v} \cdot D_{m \max } \cdot n_{m}^{2}}{3600}+\frac{C_{m f} \cdot n_{m} \cdot D_{m \max } \cdot p_{h}}{60}\right) .
\end{aligned}
$$

It can be seen from the efficiency model that the main parameters affecting the efficiency of the system are pump and hydraulic motor maximum displacement, rotation speed, and working pressure.

\section{Experimental Research on Hydraulic- Electromotor Hybrid System}

As is shown in Figure 3, the experiment table is built to verify the designed hybrid system and the mathematic model. Planetary gears and torque coupled gears are often used for hybrid electric vehicle [22]. In order to improve the performances of series-parallel $\mathrm{HEV}$, the researches proposed novel hybrid transmission systems $[23,24]$. So, the hydraulic-electromotor hybrid power system in this paper is designed by referring to the transmission scheme of hybrid electric vehicle. The hybrid powertrain structure can connect pump, hydraulic motor, electric motor, and load simultaneously. In order to simulate the positive and negative torques of beam pumping unit, magnetic powder clutch and magnetic powder brake are designed.

Figure 4 is the experimental station of the mechanical -hydraulic hybrid system according to the principle of Figure 3. According to experience, vibration and noise will occur when the design precision of transmission parts is not high. Considering the safety and stability of the experimental station, the experimental speed maximum value is $730 \mathrm{r} /$ min. A belt pulley is added between the motor and the hybrid power system, and its transmission ratio is 2 . Torque sensor (1) measures output torque of the variable frequency motor. According to the feedback torque data of the sensor (1), the displacement of the pump and hydraulic motor is precisely adjusted. Torque sensor (2) is adopted to measure the output torque of the beam pumping unit, and the

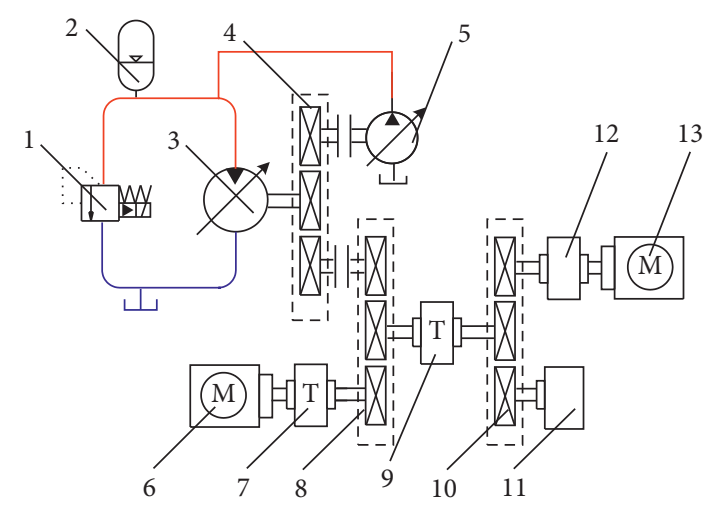

FIgURE 3: Sketch diagram of the experiment station. 1. Overflow valve; 2. Accumulator; 3. Variable-displacement pump; 4. Gear coupling group (1); 5. Variable-displacement motor; 6. Variable frequency motor; 7. Torque and speed sensor (1); 8. Gear coupling group (2); 9. Torque and speed sensor (2); 10. Gear coupling group (3); 11. Magnetic powder brake; 12. Magnetic powder clutch; 13.DC motor.

working process of the beam pumping unit is simulated by close-loop controlling magnetic powder brake and clutch. The measurement and control system of the experimental station mainly includes industrial control computer (IPC), PCI bus communication, data acquisition card, signal conditioning circuit, and control board card. This experimental system uses RTX as the lower machine and Lab Windows as the upper computer. The control cycle of the real-time measurement and control system can reach $0.5 \mathrm{~ms}$. Experimental station control system is shown as Figure 5.

This study takes the beam pumping unit of model CYJ10-3-37HB as the research object. This type of pumping unit adopts the method of crank load balance and the manufacturer provided some technical data of the pumping unit. The load fitting curve of the pumping unit is obtained through these technical data and it is used in the simulation and experiments. According to the real application, the hybrid power system is mainly used outdoors, so the system temperature will hardly change. The experimental temperature is set stable at $20^{\circ} \mathrm{C}$ and all the characteristics of the hydraulic oil are considered constant. In order to simulate the dynamic torque of the shaft of the beam pumping unit, magnetic powder clutch and magnetic powder brake are designed. That is because in the real application, torque of the transmission shaft is time-varying, and the torque curve can cross the zero line. Magnetic powder brake can realize the simulation of positive torque, and negative torque can be simulated by Dc motor and magnetic powder clutch. The parameters of experimental main components are shown in Table 1.

As shown in Figure 6, the load fitting curve fluctuates, which will cause the electromotor output torque to follow it. When the test system input load fitting curve, the experimental curve $a$ is obtained which is the output torque of the motor without the hybrid power system. Experimental curve $a$ is consistent with the load fitting curve, which verifies the effectiveness of the experimental system. The amplitude range of the experimental curve $a$ is about -1 to $12 \mathrm{~N} \cdot \mathrm{m}$ and 


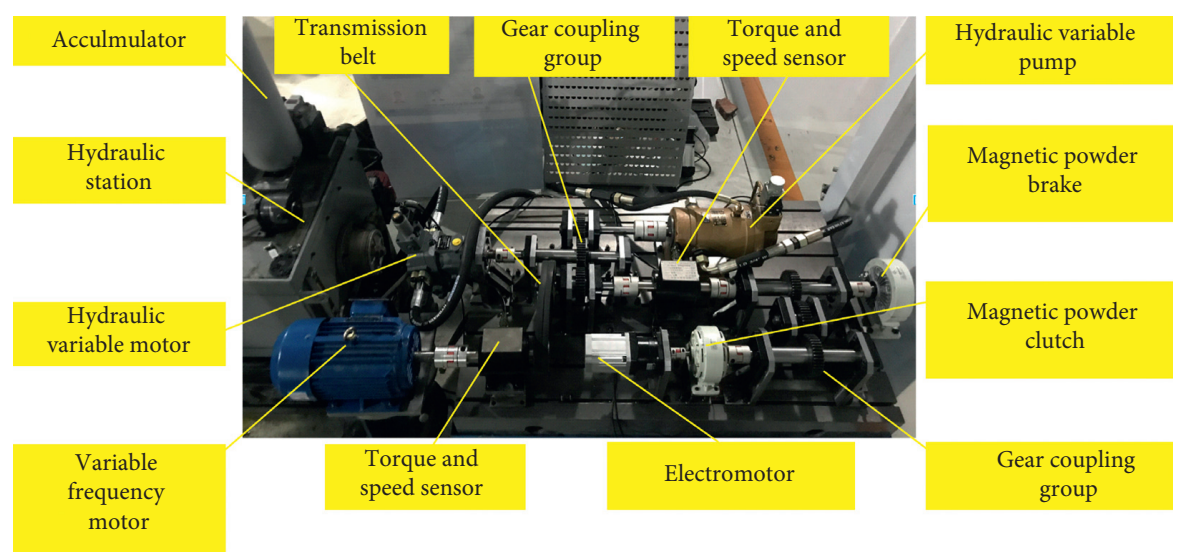

FIGURE 4: Experimental station of the hydraulic-electromotor hybrid system.

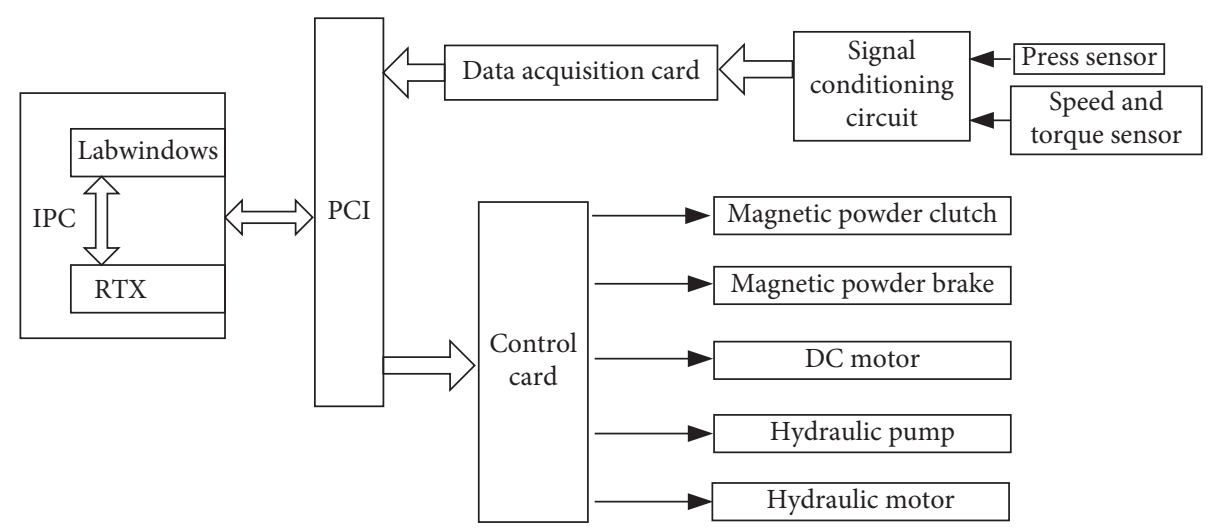

FIgURE 5: Experimental station control system.

TABLE 1: Parameters of the experimental main components.

\begin{tabular}{|c|c|c|}
\hline Components & Type & Parameters \\
\hline Axial piston variable pump & BCY14-1B-25 & $\begin{array}{c}\text { Maximum displacement: } 25 \mathrm{cc} / \mathrm{r} \\
\text { Nominal pressure: } 31 \mathrm{MPa} \\
\text { Rated speed: } 3000 \mathrm{rpm}\end{array}$ \\
\hline Axial piston variable motor & A6VM28EP12FZ & $\begin{array}{c}\text { Maximum displacement: } 28 \mathrm{cc} / \mathrm{r} \\
\text { Nominal pressure: } 35 \mathrm{MPa} \\
\text { Rated speed: } 4700 \mathrm{rpm} \\
\text { Rated power: } 2.2 \mathrm{~kW}\end{array}$ \\
\hline Three-phase asynchronous motor & Y100L-4 & $\begin{array}{l}\text { Rated speed: } 1450 \mathrm{rpm} \\
\text { Rated torque: } 5 \mathrm{~N} \cdot \mathrm{m}\end{array}$ \\
\hline Magnetic powder brake & FZ25 J & $\begin{array}{c}\text { Power supply voltage: } 24 \mathrm{~V} \\
\text { Power supply current: } 0.5 \mathrm{~A} \\
\text { Rated torque: } 6 \mathrm{~N} \cdot \mathrm{m}\end{array}$ \\
\hline Magnetic powder clutch & FL6J & $\begin{array}{l}\text { Maximum speed: } 1500 \mathrm{r} / \mathrm{min} \\
\text { Power supply voltage: } 24 \mathrm{~V} \\
\text { Power supply current: } 0.9 \mathrm{~A}\end{array}$ \\
\hline $\begin{array}{l}\text { Dc motor } \\
\text { Accumulator }\end{array}$ & $\begin{array}{l}\text { 80BL110S50 } \\
\text { NXOA6.3L }\end{array}$ & $\begin{array}{c}\text { Nominal power: } 500 \mathrm{~W} \\
\text { Volume: } 6.3 \mathrm{~L}\end{array}$ \\
\hline Torque and speed sensor & JN-DN28 & $\begin{array}{l}\text { Range of the input signal: } 1 \sim 5 \mathrm{~V} \\
\text { Range of the detect torque: } 0 \sim 30 \mathrm{Nm}\end{array}$ \\
\hline Pressure sensor & SIN-P300 & $\begin{array}{l}\text { Power supply voltage: } 24 \mathrm{~V} \\
\text { Output current: } 4-20 \mathrm{~mA}\end{array}$ \\
\hline
\end{tabular}

part of the curve crosses the zero line. The load curve fluctuates greatly and even produces negative torque which will lead to the low efficiency of the electromotor.
Experimental curve $b$ is the output torque curve of the motor with hybrid power system and the torque of the motor can be stabilized between 5 and $7 \mathrm{~N} \cdot \mathrm{m}$ when the load changes. This 


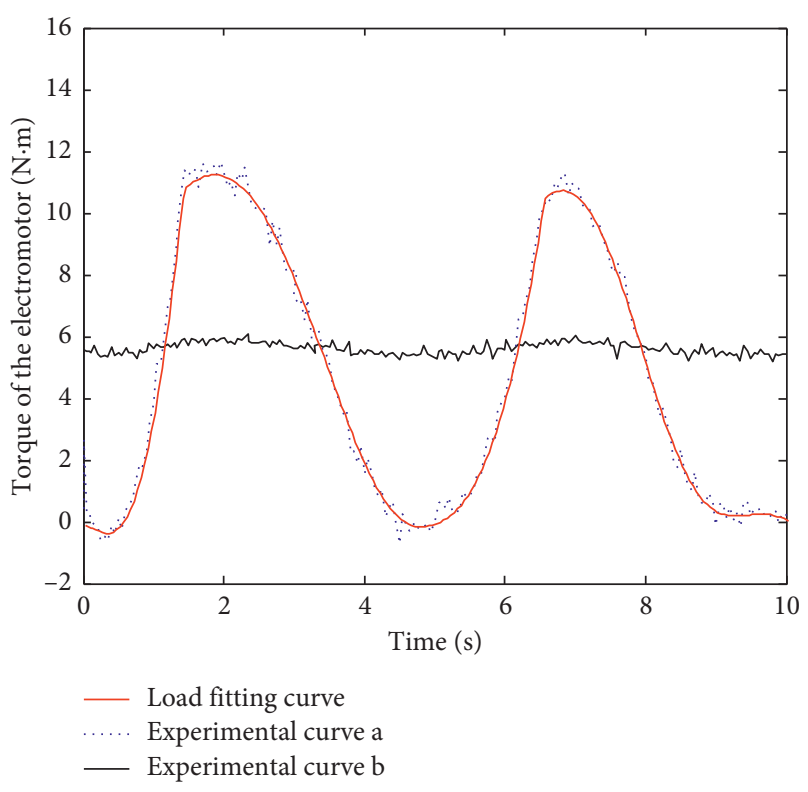

FIgURE 6: Comparison of experimental results of motor torque.

is because, in the process of dynamically adjusting the displacement of the pump and hydraulic motor, the output torque of the hydraulic system follows the change of the load, and the motor torque can remain stable, and this means that the electromotor has higher efficiency.

The correctness of the mathematical model and energysaving method is verified by simulation and experiment. As the hybrid system efficiency affects its energy-saving effect, it is necessary to research the parameters that affect efficiency. According to the efficiency model of the hydraulic-electromotor hybrid power system, the parameters affecting the efficiency of the system include pressure, displacement, and rotation speed. So, the influence parameters of the efficiency of the hybrid system should be further verified by the experimental study.

4.1. Effect of System Working Pressure. The hydraulic-electromotor hybrid system works under different pressures and the energy loss is different. It is necessary to study the effect of pressure on system efficiency. Experimental pressure is set to $6,10,14$, and $18 \mathrm{MPa}$, and the hybrid system speed is set to $730 \mathrm{r} / \mathrm{min}$. Because of the system input energy flowing through the motor, the influence of pressure on the system efficiency can be studied by collecting the output torque of the motor. Simulation and experimental dynamic curves are as follows:

As shown in Figure 7, the output torque of the motor increases when the pressure is higher. This indicates that the energy loss of the hybrid system increases and the efficiency of the hybrid system decreases. The results of the simulation and experiment are consistent with each other. The emergence of this result is because for the same load, according to the energy regulation principle, the hydraulic system always stores and releases the same energy under a different working press. When the speed of the hybrid system is constant, the hydraulic system will store different volume liquid under a different working press. Variable pump and variable hydraulic motor should work with high efficiency at maximum displacement. But when the hybrid system is working under higher pressure, pump and hydraulic motor displacement value is smaller and less liquid is stored. In this time, the efficiency of the pump and the hydraulic motor is lower and the energy input from the electromotor to the system increases, and the motor output torque increases. The experimental results show that the efficiency of the hydraulic-electromotor hybrid system is different under different pressure conditions, and the selection of the correct pump and hydraulic motor maximum displacement value will effectively improve the efficiency of the system.

\subsection{Effect of Maximum Displacement of Pump and Hydraulic} Motor. Two different maximum displacement fixed pumps are used in the experiment, and the maximum displacement value is $10 \mathrm{cc} / \mathrm{r}$ and $16 \mathrm{cc} / \mathrm{r}$, respectively. During the experiment, only the displacement of the hydraulic motor was adjusted when the speed of the hybrid system is constant. Through simulation and experimental research, the two fixed pumps meet the requirements, but the output torque of electromotor is different. Simulation and experimental dynamic curves are as follows.

As shown in Figure 8, the results of the simulation and experiment are consistent with each other. Simulation and experimental results show that the efficiency of the hybrid system is different when different pumps are selected under the same pressure, and the efficiency of the hybrid system is higher when the maximum displacement value of the pump is $10 \mathrm{cc} / \mathrm{r}$. This conclusion is consistent with Figure 7. Therefore, the pump or hydraulic motor with a small maximum displacement value should be selected as far as possible under the premise of meeting the requirements. In addition, the maximum displacement value of the pump and hydraulic motor also affects the torque loss and flow loss, and choosing a large displacement pump and hydraulic motor can lead to increased losses. Reasonable determination of pump and hydraulic motor maximum displacement value is conducive to improving efficiency.

\subsection{Effect of Rotation Speed of Pump and Hydraulic Motor.} According to the efficiency equation, speed affects the efficiency of the hydraulic-electromotor hybrid system. Under the same condition of pressure and maximum displacement, the experiment was carried out by changing the rotating speed of the hydraulic-electromotor hybrid system. Load power is the same when the experiment speed of the hybrid system is set to 730 and $530 \mathrm{r} / \mathrm{min}$, respectively. Simulation and experimental dynamic comparison curves are as follows.

As shown in Figure 9, the results of the simulation and experiment are consistent with each other. The output power of the electromotor is different under different speed of hybrid system which suggests that the hybrid system efficiency is affected by rotation speed. According to the experimental results, the output power of the motor at the speed of $730 \mathrm{r} / \mathrm{min}$ is greater than that at 530RPM and the efficiency of the hybrid system is higher at $530 \mathrm{r} / \mathrm{min}$. 


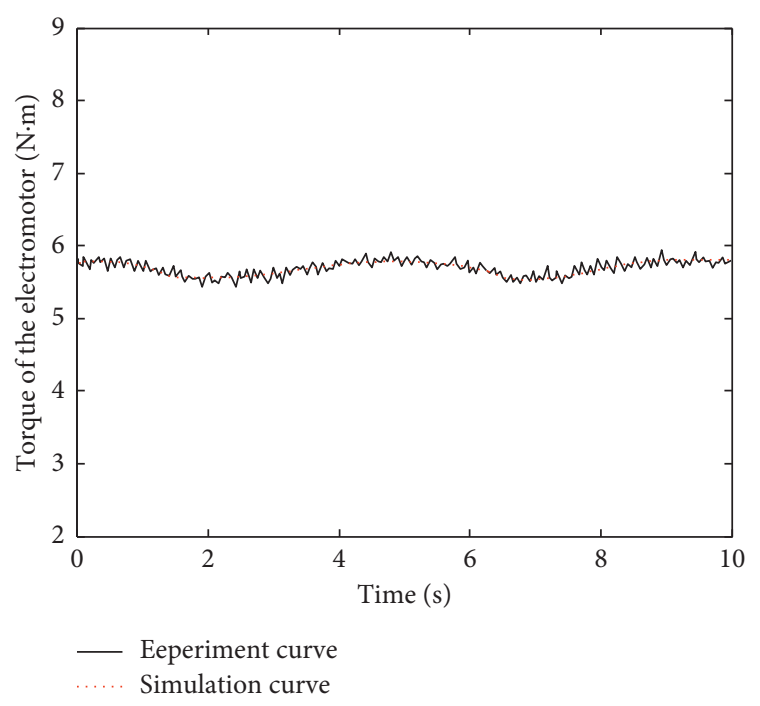

(a)

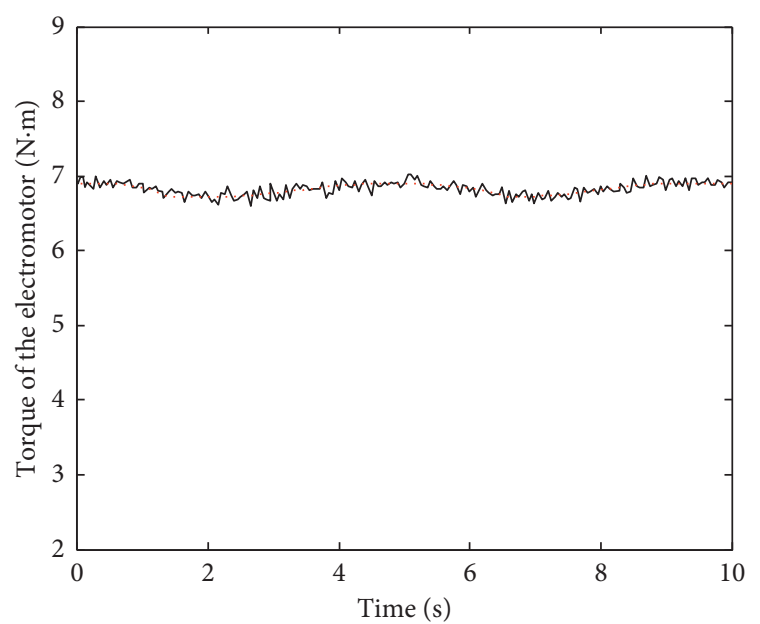

- Eeperiment curve Simulation curve

(c)

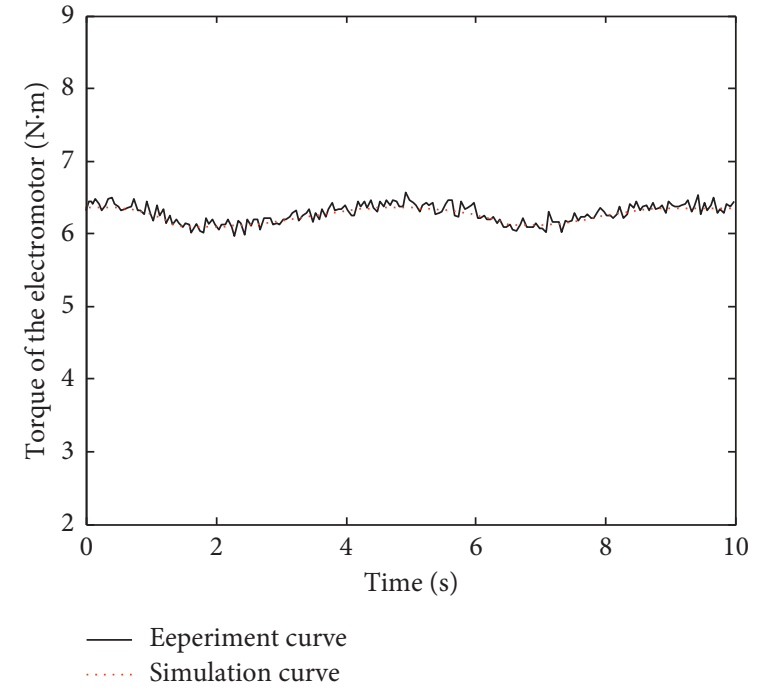

(b)

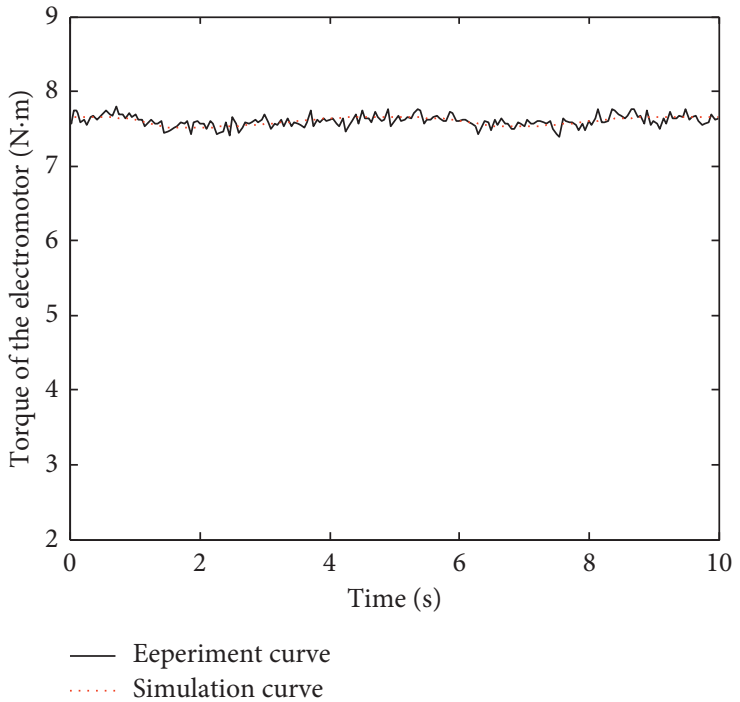

(d)

FIGURE 7: Electromotor output torque comparison curves under different pressures. (a) $6 \mathrm{MPa}$; (b) $10 \mathrm{MPa}$; (c) $14 \mathrm{MPa}$; (d) $18 \mathrm{MPa}$.

The effects of rotational speed, working pressure, and maximum displacement and the correctness of the efficiency model were verified by experiments, but the influence rule of different parameters on hybrid system efficiency was not studied due to the limited experimental conditions. In order to realize the engineering application of the hydraulic-electromotor hybrid system on the pumping unit, based on the experimental results, the influence of parameters on system efficiency should be further studied. Without considering the energy loss, the output torque of the electromotor can be a constant value through changing the displacement of the pump and hydraulic motor, and it should be the load torque average $\bar{T}_{L}$. According to equation (17), the following equation is established:

$$
\frac{\bar{p}_{h}}{2 \pi} \cdot\left(D_{m}-D_{p}\right) \cdot i_{1}+\frac{\bar{T}_{L}}{i}=\frac{T_{L}}{i} .
$$

Because the accumulator can stabilize the pressure, when the load reaches the maximum and minimum, the pressure is equal to the average pressure $\bar{p}_{h}$. Therefore, the following equations are established:

$$
\begin{aligned}
& \frac{\bar{p}_{h}}{2 \pi} \cdot\left(D_{m \max }-D_{p \min }\right) \cdot i_{1}=\frac{T_{L \max }-\bar{T}_{L}}{i}=\Delta T_{\max }, \\
& \frac{\bar{p}_{h}}{2 \pi} \cdot\left(D_{\text {min }}-D_{p \max }\right) \cdot i_{1}=\frac{T_{L \min }-\bar{T}_{L}}{i}=\Delta T_{\min } .
\end{aligned}
$$

According to equations (1) and (6), the maximum displacement value of the pump and hydraulic motor can be obtained as follows: 


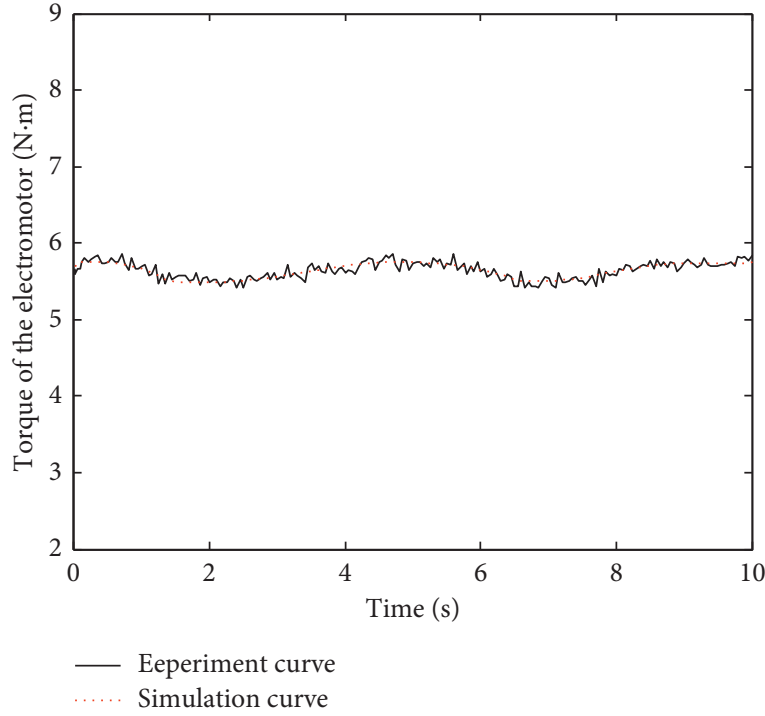

(a)

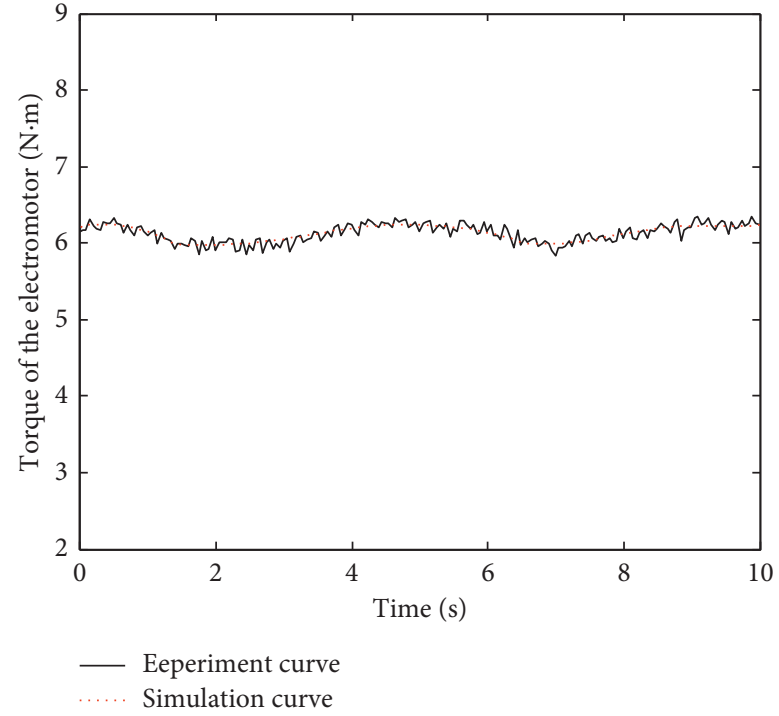

(b)

FiguRE 8: Electromotor torque comparison curves under different displacements of the pump. (a) The maximum displacement pump is $10 \mathrm{cc} / \mathrm{r}$; (b) The maximum displacement pump is $16 \mathrm{cc} / \mathrm{r}$.

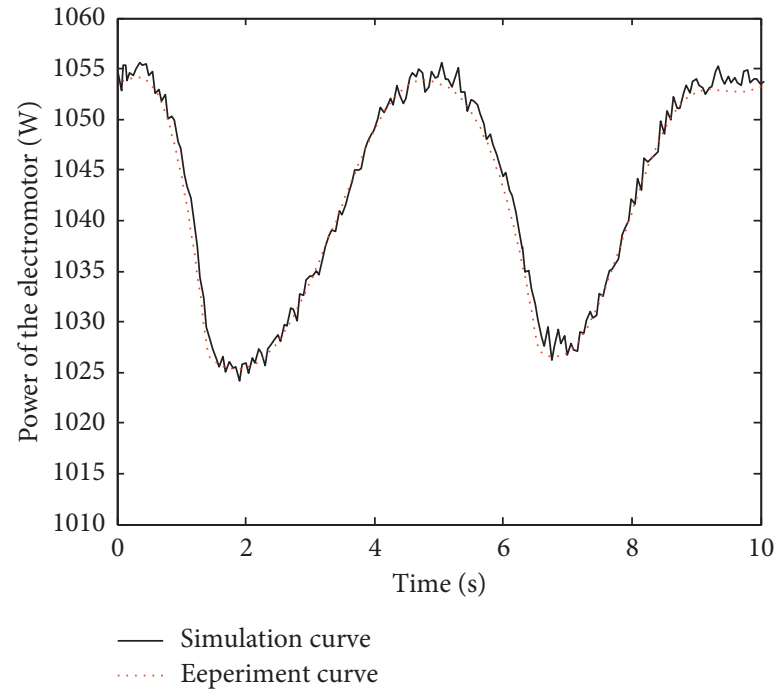

(a)

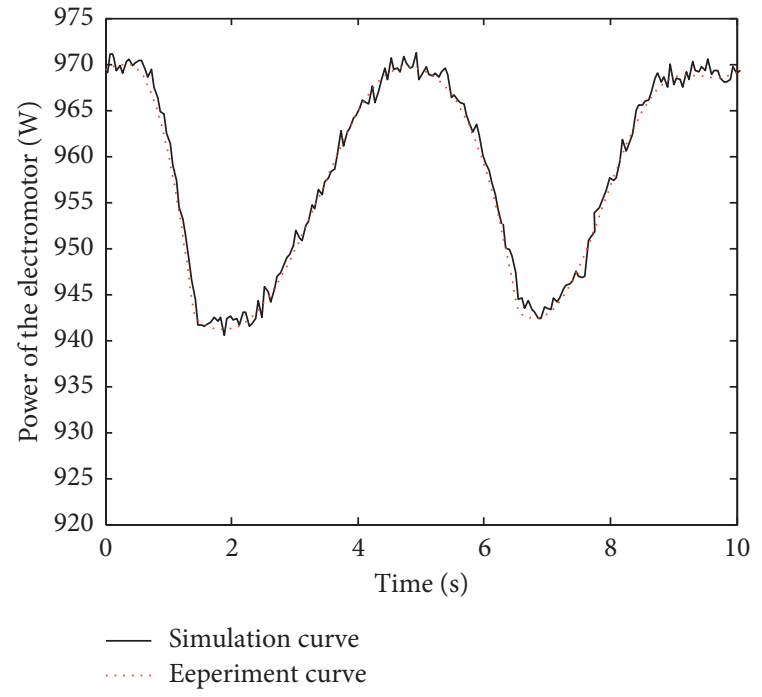

(b)

FIGURE 9: Electromotor power comparison curves under different speed of hybrid system. (a) The speed of the hybrid system is $730 \mathrm{r} / \mathrm{min}$; (b) The speed of the hybrid system is $530 \mathrm{r} / \mathrm{min}$.

$$
\begin{aligned}
D_{p \max } & =\left(\Delta T_{\text {max }}-\frac{\Delta T_{\text {min }}}{\beta_{\text {mmin }}}\right) \cdot \frac{2 \pi}{i_{1} \cdot \bar{p}_{h}} \cdot \frac{\beta_{\text {mmin }}}{\beta_{p \min }}, \\
D_{\text {mmax }} & =\left(\frac{1}{\beta_{p \min }} \cdot \Delta T_{\text {max }}-\frac{\Delta T_{\text {min }}}{\beta_{\text {mmin }} \cdot \beta_{p \min }}+\frac{\Delta T_{\text {min }}}{\beta_{\text {mmin }}}\right) \cdot \frac{2 \pi}{i_{1} \cdot \bar{p}_{h}} .
\end{aligned}
$$

This simplified method designs the maximum displacement value of pump and hydraulic motor. This will lead to torque small fluctuation but meet the needs of regulation.
Considering the energy loss, the output torque and power equation of the motor are as follows:

$$
\begin{aligned}
& T_{e}=\frac{P_{\text {loss }}}{n_{e}} \cdot \frac{30}{\pi}+\frac{\bar{T}_{L}}{i}, \\
& P_{e}=P_{\text {loss }}+\frac{\bar{T}_{L}}{i} \cdot n_{e} \cdot \frac{\pi}{30} .
\end{aligned}
$$

According to equations (22), (25), and (26), the efficiency of the hybrid system is mainly determined by $\bar{p}_{h}, i_{1}, \beta_{p \text { min }}$, 
and $\beta_{m \text { min }}$, and reasonable parameter optimization design can effectively improve the system efficiency.

\section{Optimization Research on the Hydraulic- Electromotor Hybrid System}

In order to further research the influence of parameters on hybrid system efficiency, the system simulation model is established. This paper uses AMEsim-MATLAB united simulation. The load model of the beam pumping unit is established by AMEsim software. In the load model, this paper simulates the pumping unit of type CYJ10-3-37HB, and the parameters of the four-bar mechanism are set according to the trim size of the pumping unit. The type of the motor is Y280S-8, rated power is $37 \mathrm{~kW}$, and rated speed $n_{e}$ is $730 \mathrm{r} / \mathrm{min}$. The working stroke appropriate is $2 \mathrm{~m}$. The working frequency of the walking beam is 6 times $/ \mathrm{min}$. The total transmission ratio of pumping unit $i$ is 120 . The simulation model of the AMEsim software is shown in Figure 10.

The mechanical hydraulic hybrid system model is established by Matlab software and the specific structure is shown in Figure 11. It mainly includes pump, hydraulic motor, electromotor, and accumulator, and so on. Meanwhile, this paper mainly studies the efficiency under various operating conditions and analyzes the working conditions that must be controlled in order to achieve higher efficiency. The system adopts an axial piston pump and motor as the main hydraulic components. In order to simplify the problem, the clearance change of the pump and the hydraulic motor are ignored during operation. The loss coefficient under maximum displacement can be used as the simulation value to meet the research needs according to the operating conditions and consulting manufacturers. Therefore, the simulation parameters of the beam pumping unit and hydraulic system are shown in Table 2.

\subsection{Effect of Displacement Ratio of the Pump and Hydraulic} Motor. According to the simulation and experimental results, the maximum displacement of the pump and hydraulic motor affects the efficiency of the hybrid system. When ${ }^{-} p_{h}$, $i_{1}$, and $n_{e}$ are constant, $D_{p \max }$ and $D_{m \text { max }}$ are determined by $\beta_{p \min }$ and $\beta_{m \text { min }}$. Different combinations of displacement have a different energy-saving effect. Therefore, $\beta_{p \text { min }}$ is set to $0.1,0.2,0.3,0.4$, and 0.5 when $\beta_{\text {mmin }}$ is set to $1, \bar{p}_{h}$ is set to $10 \mathrm{MPa}$, and $i_{1}$ is set to 1 . Through changing the different values of $\beta_{p \min }$, the different displacement combinations are shown in Figure 12. $D_{p \max }$ and $D_{m \max }$ increase with the change of $\beta_{p \min }$, which will lead to more costs. The smaller value of the $\beta_{p \min }$ is conducive to reduce the cost.

As shown in Figure 13, the displacement ratio of pump $\beta_{p}$ changes when the load changes during a cycle of the pumping unit. This suggests that the displacement of the pump is controlled and the output torque of the hydraulic system follows the load, and the electromotor torque output keeps stable. Although the value of $\beta_{p \min }$ is different, pump and hydraulic motor maximum displacement combinations can meet the use requirements. Therefore, this design

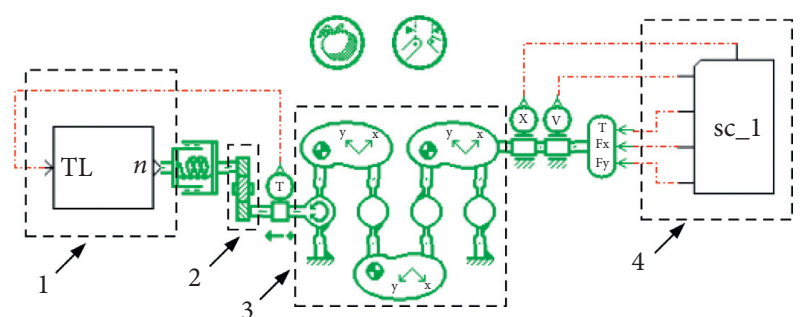

Figure 10: Beam pumping unit model. 1. Simulink-AMESim interface model; 2. Speed reducer model; 3. Four-link mechanism model; 4. Polished rod load.

method of $D_{p \max }$ and $D_{m \text { max }}$ is feasible. The smaller value of $\beta_{p \text { min }}$, the more the range of the displacement of the pump changes.

The output torque curves of the electromotor are shown in Figure 14. Torque is stabilized by change pump displacement. With $\beta_{p \min }$ increases, the torque of the electromotor increases. This indicates that the system loses more power. The maximum displacement value of the pump affects the energy loss. As shown in Figure 15(a), system efficiency varies with the load. When $\beta_{p \min }$ is set to 0.1 , the maximum system efficiency can reach $90 \%$. When $\beta_{p \text { min }}$ is 0.5 , the minimum system efficiency is $76 \%$. As shown in Figure 15(b), the system efficiency decreases with the increase of $\beta_{p \min }$. As the displacement ratio affects the maximum displacement of the pump and the maximum displacement value affects the loss of the system, so the system efficiency will reduce when $\beta_{p \text { min }}$ increases. At the same time, a larger maximum displacement value means an increase in costs. Therefore, $\beta_{p \text { min }}$ should be set to smaller value.

In another way, when $\beta_{p \min }$ is equal to 1.0 , and $\beta_{m \text { min }}$ is set to $0.1,0.2,0.3,0.4$, and 0.5 , and the same conclusion can be obtained. When changing both the parameters simul$\operatorname{taneously}\left(\beta_{m \min }\right.$ is set to $0.2,0.4,0.6$, and 0.8 , and $\beta_{p \min }$ is set from 0.2 to 0.8 ), then the efficiency comparison curves can be shown as Figure 16. When both the parameters are set to smaller values, the system efficiency will be higher. When $\beta_{p \min }$ and $\beta_{m \text { min }}$ are set to 0.2 , the maximum efficiency of the hybrid system is 0.93 . What is more, there is no coupling between the two parameters when they affect the changing trend of the system efficiency. The products of the pump and hydraulic motor have the minimum requirement, and according to different types of the axial plunger pump and hydraulic motor, the minimum displacement ratio is from 0 to 0.2 . In this paper, the ratio is selected to be 0.2 . At the same time, a similar simulation was carried out through changing the pressure and transmission ratio, and the same conclusion is obtained, which demonstrates the influencing characteristics of $\beta_{p \min }$ and $\beta_{m \text { min }}$ once again.

5.2. Effect of Pressure of the Hybrid System. In this section, $\beta_{m \text { min }}$ and $\beta_{p \text { min }}$ are equally set to 0.2 . The pressure changing effect is analyzed when the transmission ratio $i_{1}$ is set to 1.0. Experimental studies have shown that the pressure of the hydraulic system directly influences the stored power of the 


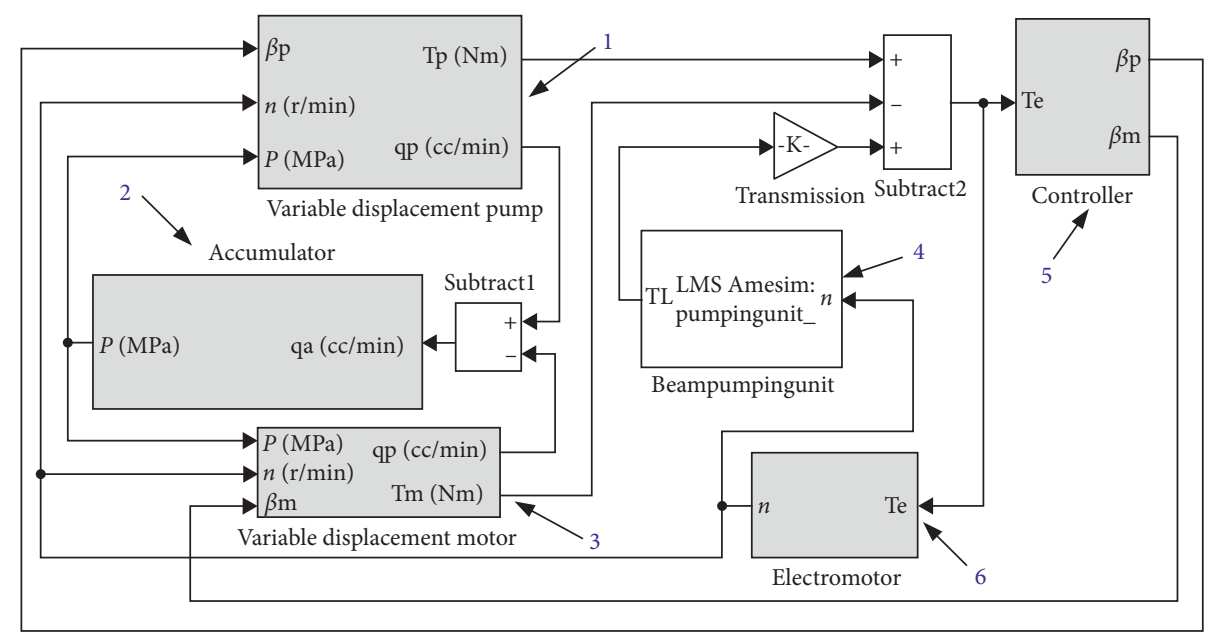

Figure 11: Hydraulic-electromotor hybrid system model. 1. Variable-displacement pump model unit; 2. Accumulator model unit; 3. Variable-displacement motor model unit; 4. Pumping unit model; 5. Controller model unit; 6. Electromotor model unit.

TABLE 2: Simulation parameters.

\begin{tabular}{lc}
\hline Parameter & Value \\
\hline$C_{p s}$ & $0.8 \times 10^{-9}$ \\
$C_{p v}$ & $2 \times 10^{5}$ \\
$C_{p f}$ & 0.01 \\
$\mu$ & $0.051 \mathrm{P}_{\mathrm{a}} \mathrm{s}$ \\
$n_{e}$ & $730 \mathrm{r} / \mathrm{min}$ \\
$T_{L \min }$ & $-0.87 \mathrm{kN} \cdot \mathrm{m}$ \\
$C_{m s}$ & $1.6 \times 10^{-9}$ \\
$C_{m v}$ & $1.25 \times 10^{5}$ \\
$C_{m f}$ & 0.01 \\
$V_{0}$ & $5 \mathrm{~L}$ \\
$T_{L \max }$ & $20 \mathrm{kN} \cdot \mathrm{m}$ \\
$T_{L}$ & $10 \mathrm{kN} \cdot \mathrm{m}$ \\
\hline
\end{tabular}

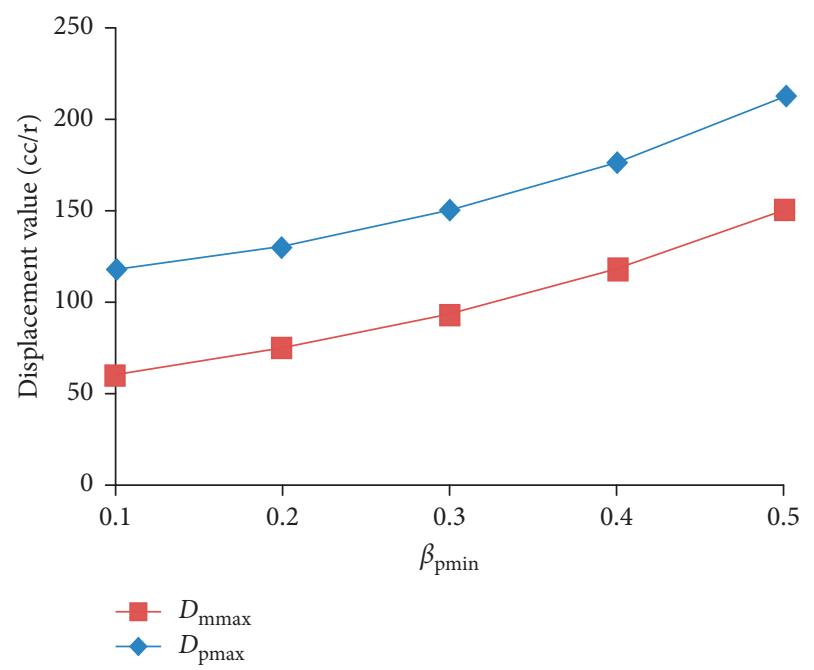

Figure 12: Pump and hydraulic motor maximum displacement combination.

accumulator as well as the output flow of the pump and hydraulic motor. The pressure of the hydraulic system is set to $5,10,15,20,25$, and $30 \mathrm{MPa}$, respectively. As is shown in

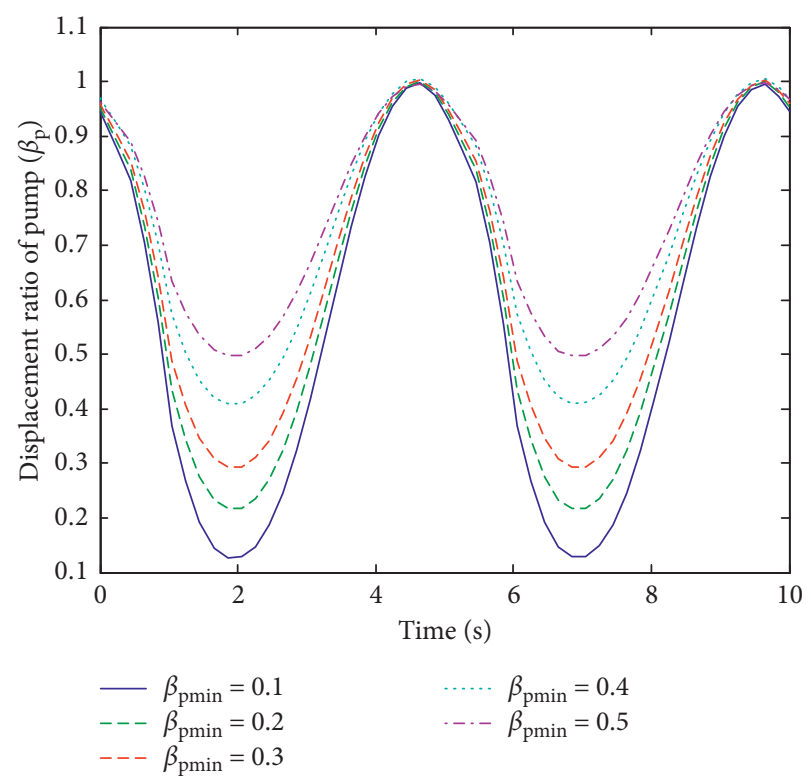

FIgURE 13: Dynamic curve of displacement ratio change of pump.

Figure 17, according to the different pressures, the optimal displacement combinations between the pump and hydraulic motor are obtained. Through the simulation results, when the pressure is higher, the optimum maximum displacement value is smaller, which can save the cost of the whole system.

Simulation studies were carried out under different pressures and different maximum displacement combinations, and the motor torque output curve obtained was shown in Figure 18. When the pressure is $10 \mathrm{MPa}$, the motor output torque is the least, which means the system power loss is the least. When the pressure is $5 \mathrm{MPa}$ and $20 \mathrm{MPa}$, the motor output torque is near, which means the system power loss is the same. This suggests that the hybrid system should choose the working pressure of $10 \mathrm{MPa}$ when the transmission ratio of the hybrid system is 1 . 


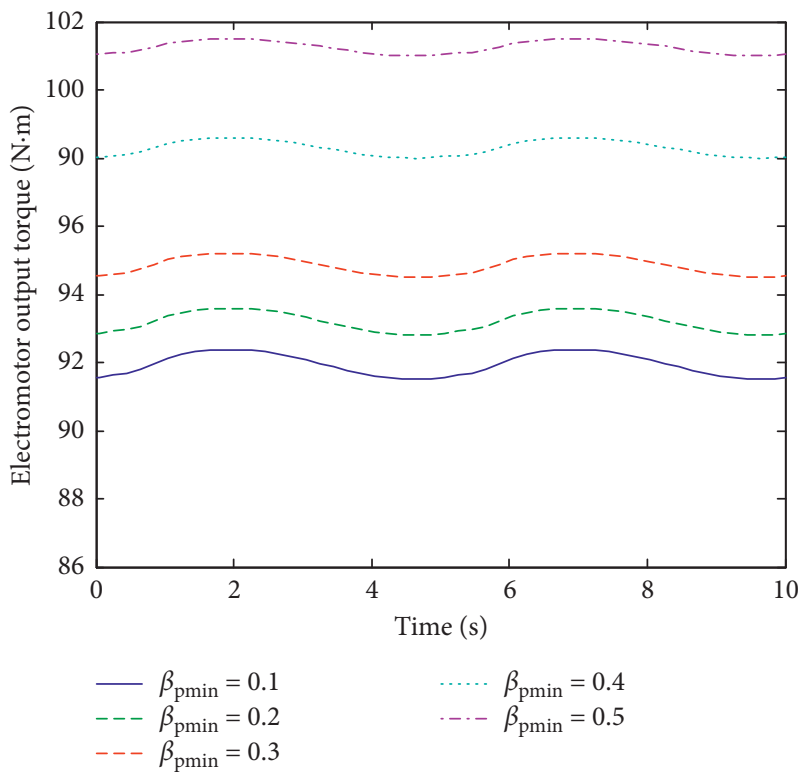

FIGURE 14: Electromotor output torque curves.

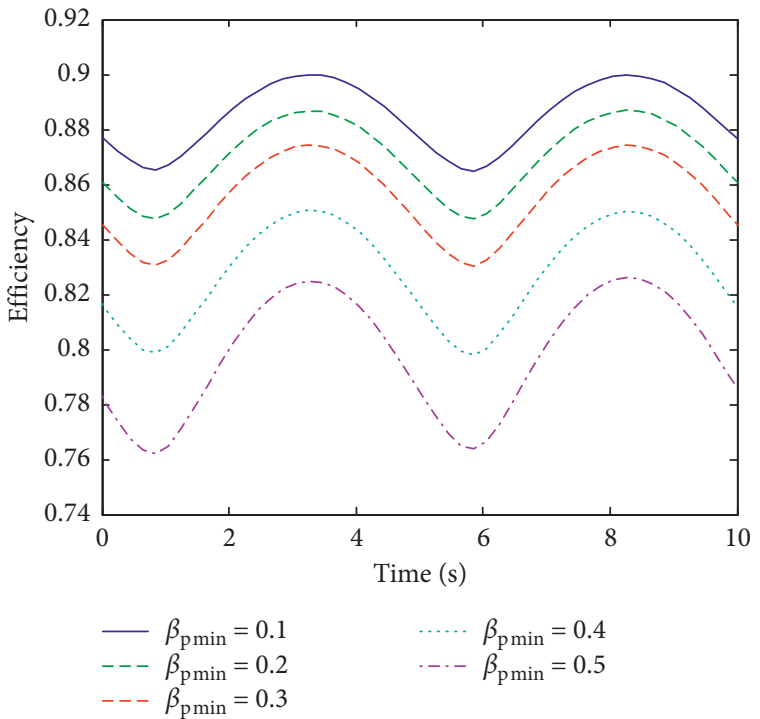

(a)

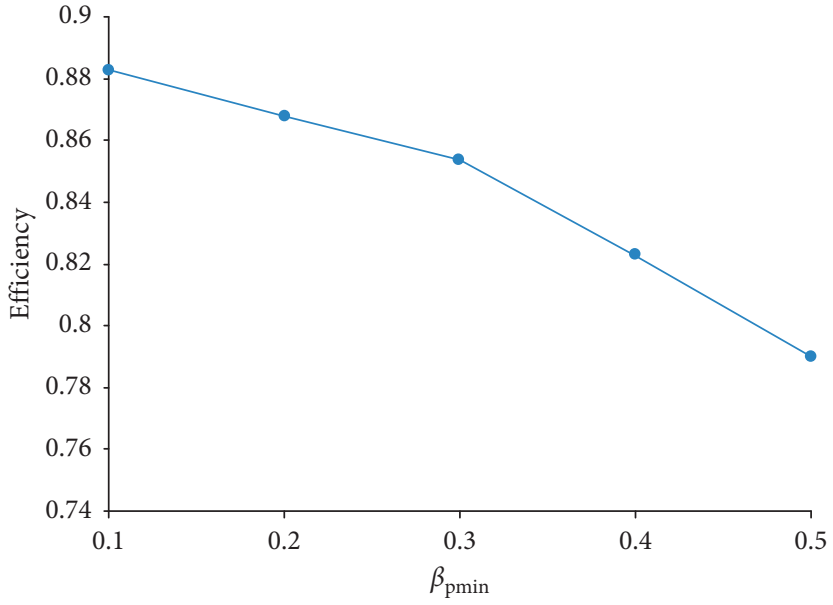

(b)

FIGURE 15: Whole efficiency curves influenced by $\beta_{p \text { min. }}$. (a) Dynamic efficiency curves; (b) Scatter points of the efficiency influenced by $\beta_{p \text { min }}$

As shown in Figure 19(a), the system efficiency is different under different pressure. When the pressure is $10 \mathrm{MPa}$ and the maximum displacement of the pump and motor is $80 \mathrm{cc} / \mathrm{r}$, the hybrid system efficiency increase to 0.91 . As shown in Figure 19(b), when the working pressure of the system is higher than $10 \mathrm{MPa}$, the system efficiency reduces with the increase of the pressure. When the system pressure is at $30 \mathrm{MPa}$, the lowest efficiency is 0.88 .

5.3. Effect of the Rotation Speed of the Hybrid System. Similarly, $\beta_{m \text { min }}$ and $\beta_{p \min }$ are equally set to 0.2 , when changing the transmission ratio $i_{1}$, then the output speed of the hydraulic pump and motor can be changed. The different coupling speed will influence the system energy consumption. When $i_{1}$ is equal to $1.0,2.0,3.0$, and 4.0 , the corresponding coupling speed of hydraulic pump and motor is $730,1460,2190$, and 2920 RPM, respectively. When the working pressure is $15 \mathrm{MPa}$, the corresponding designed displacement value varies as shown in Figure 20. When the transmission ratio $i_{1}$ increases, the designed value of the displacement will reduce. That means pump and hydraulic motor with smaller maximum displacement can be used for energy regulation.

According to Figure 21, when the ratio is settled differently, the corresponding output efficiency is different, 


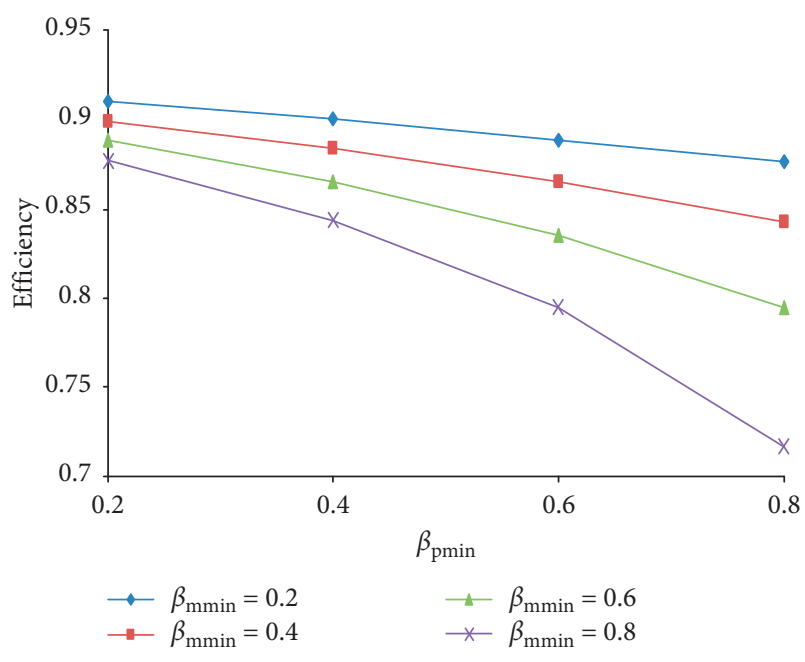

FIGURE 16: Whole efficiency curves influenced by $\beta_{p \min }$ and $\beta_{m \text { min }}$.

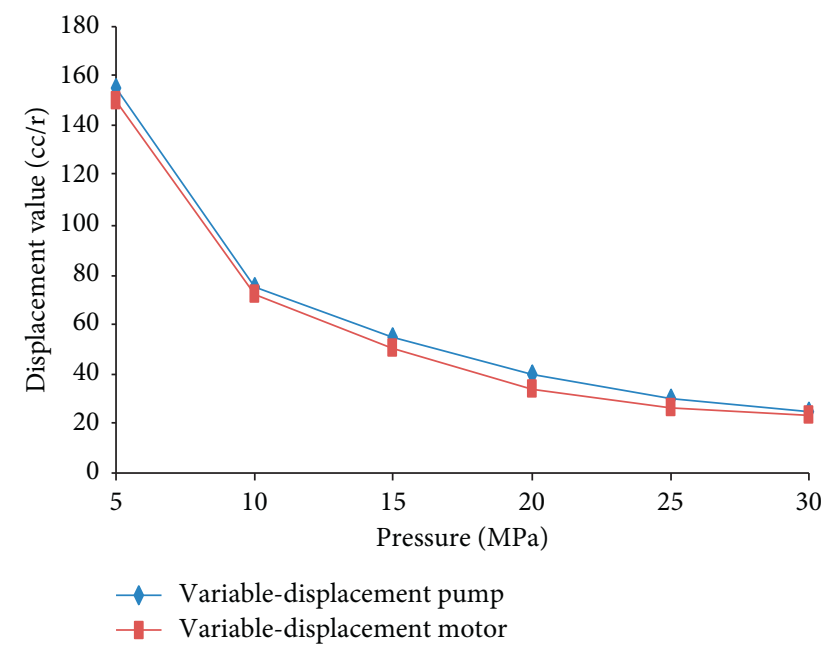

FIgURE 17: The optimal maximum displacement value combination under different pressures.

which means the system consumption is different under different output speeds. It has been proved in the experiment that the system efficiency is different with different coupling speeds. Furthermore, the higher the system consumption is, the higher the electromotor output power is. According to Figure 22, when the working pressure is constant, the system efficiency is different under different transmission ratios. In addition, when the transmission ratio is 2.0 , the pressure is $15 \mathrm{MPa}$ and the system efficiency is the highest.

According to the efficiency equations, the different pressure and transmission ratios can get different efficiency curves. Figure 23 is the combined efficiency curves with transmission and system pressure. It can be seen that there is a coupling relationship between the transmission ratio and system pressure. The maximum efficiency can be achieved under different transmission ratios corresponding to different optimal pressures. Therefore, when designing the working speed and pressure of the hybrid power system, the

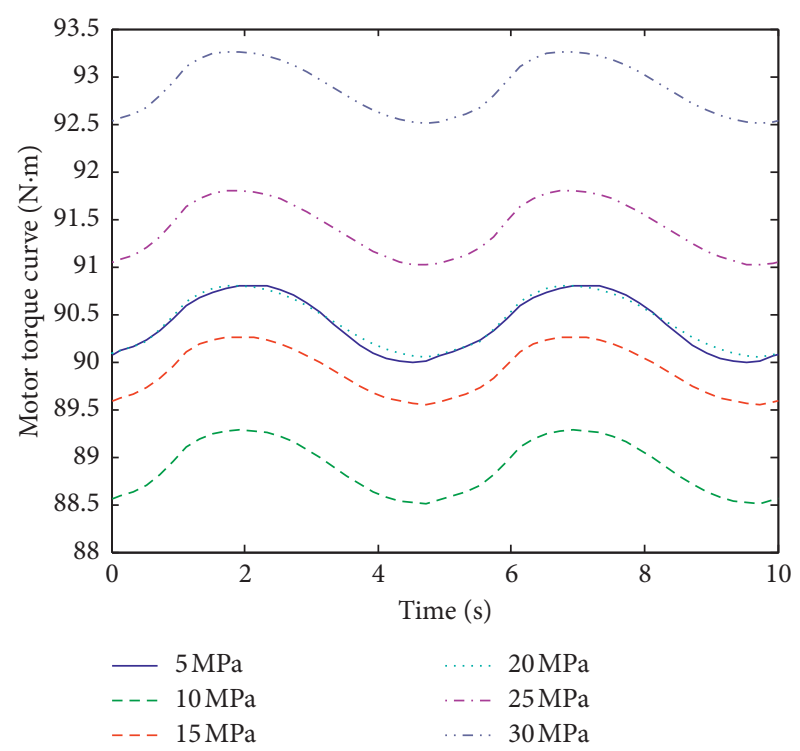

Figure 18: Electromotor output torque curve under different pressure.

mutual relationship between them should be considered comprehensively, and the maximum efficiency and minimum energy loss can be achieved under the optimal corresponding relationship.

\subsection{Optimum Relation between Pressure and Transmission} Ratio of the Hybrid System. When the displacement ratio of the pump and hydraulic motor, electromotor speed, and pumping unit load have been determined, the energy loss is mainly determined by pressure and transmission ratio of the hybrid system. Assume the following equations is true, then the energy loss model can be simplified as follows:

$$
\begin{aligned}
& a_{1}=2 \pi \cdot\left(\Delta T_{\max }-\frac{\Delta T_{\text {min }}}{\beta_{m \text { min }}}\right) \times \frac{\beta_{\text {min }}}{\beta_{p \min }}, \\
& a_{2}=\frac{C_{p s}}{\mu}, \\
& a_{3}=\frac{\mu \cdot C_{p v} \cdot n_{e}^{2}}{3600}, \\
& a_{4}=\frac{C_{p f} \cdot n_{e}}{60}, \\
& b_{1}=2 \pi \cdot\left(\frac{1}{\beta_{p \min }} \cdot \Delta T_{\text {max }}-\frac{\Delta T_{\text {min }}}{\beta_{m \text { min }} \cdot \beta_{p \text { min }}}+\frac{\Delta T_{\text {min }}}{\beta_{m \text { min }}}\right), \\
& b_{2}=\frac{C_{m s}}{\mu}, \\
& b_{3}=\frac{\mu \cdot C_{m v} \cdot n_{e}^{2}}{3600},
\end{aligned}
$$




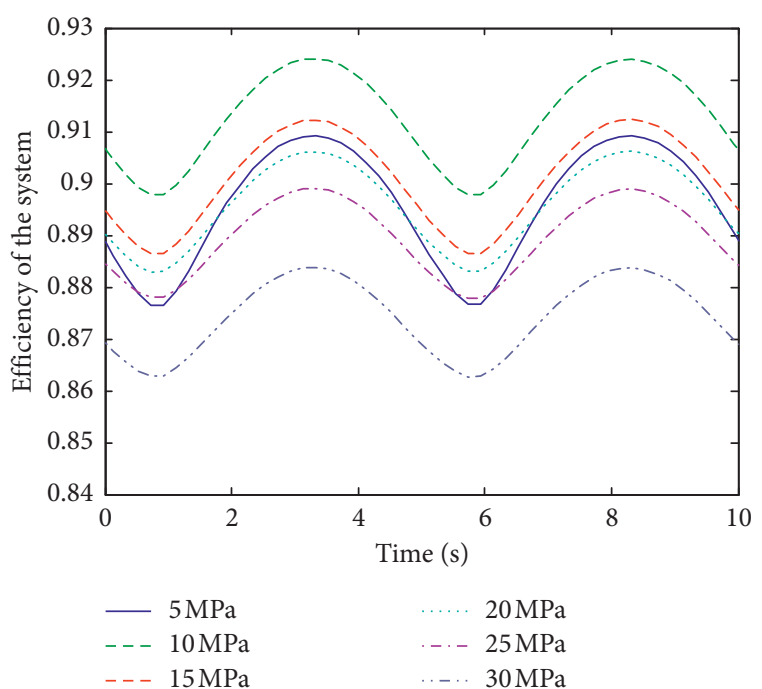

(a)

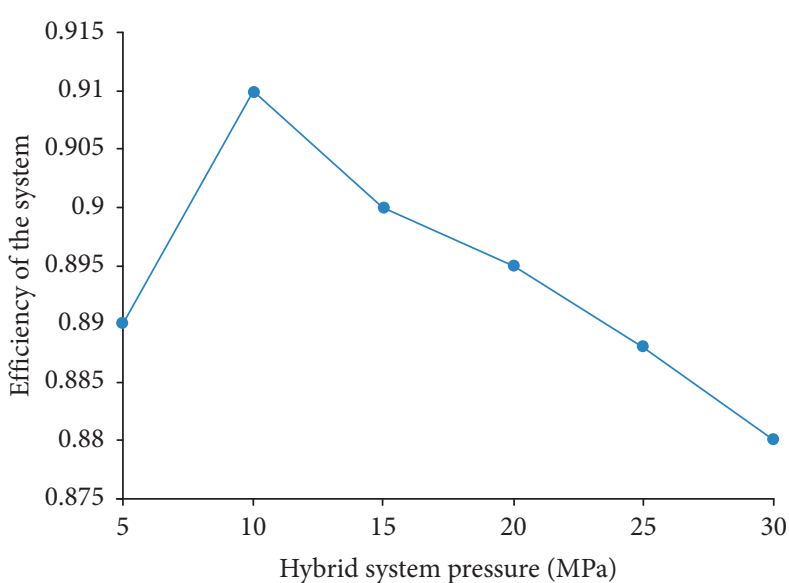

(b)

FIGURE 19: Efficiency curves of the hybrid system. (a) Dynamic efficiency curves; (b) scatter points under different hydraulic system pressures.

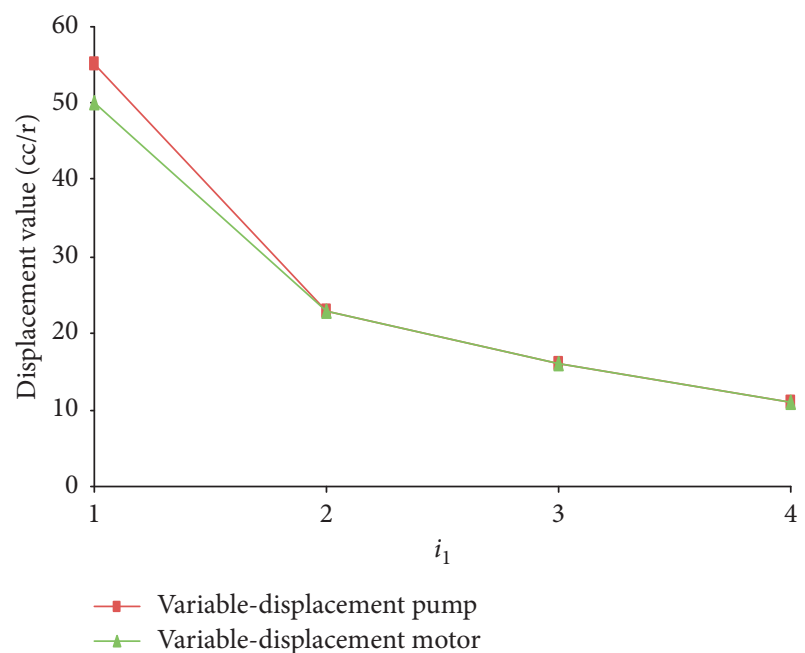

Figure 20: The optimal displacement value under different transmission ratios.

$$
b_{4}=\frac{C_{m f} \cdot n_{e}}{60}
$$

Respectively adding the above equations (29)-(26) into equations (20), (21), (25), and (26), the energy loss equation can be obtained as follows:

$$
\begin{aligned}
P_{\text {loss }}= & \frac{a_{1} \cdot a_{2} \cdot \bar{p}_{h}}{i_{1}}+\frac{a_{1} \cdot a_{3} \cdot i_{1}}{\bar{p}_{h}}+a_{1} \cdot a_{4}+\frac{b_{1} \cdot b_{2} \cdot \bar{p}_{h}}{i_{1}} \\
& +\frac{b_{1} \cdot b_{3} \cdot i_{1}}{\bar{p}_{h}}+b_{1} \cdot b_{4} .
\end{aligned}
$$

Equation (37) has the minimum value, when $\bar{p}_{h}$ and $i_{1}$ satisfy the following equation:

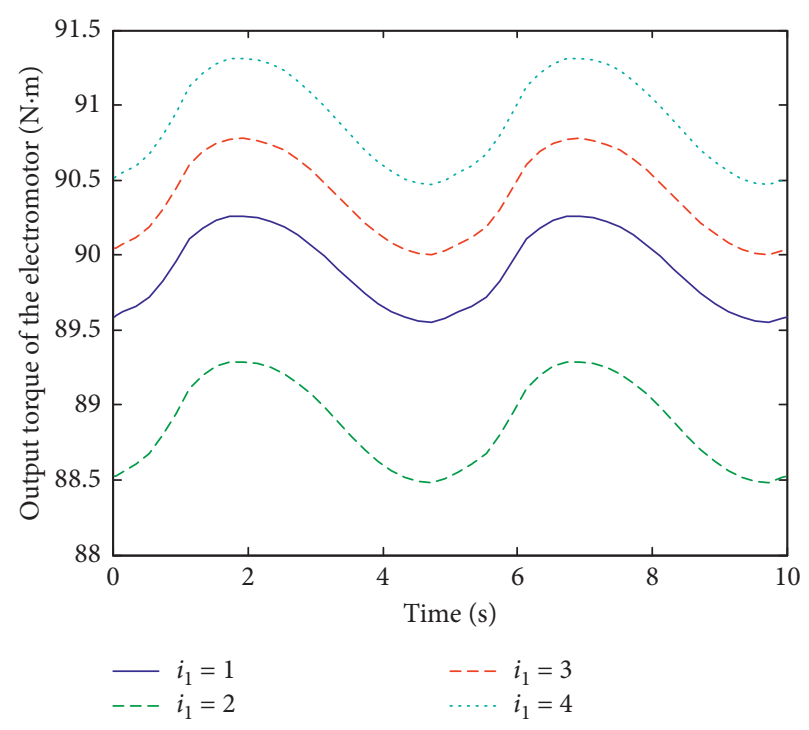

FIgURE 21: Dynamic curves of the output torque of the electromotor.

$$
\bar{p}_{h}^{2}=\frac{a_{1} \cdot a_{3}+b_{1} \cdot b_{3}}{a_{1} \cdot a_{2}+b_{1} \cdot b_{2}} \cdot i_{1}^{2}
$$

The minimum value is as follows:

$$
P_{\text {lossmin }}=2 \sqrt{\left(a_{1} \cdot a_{2}+a_{1} \cdot a_{3}\right)}+2 \sqrt{\left(b_{1} \cdot b_{2}+b_{1} \cdot b_{3}\right)},
$$

where $P_{\text {lossmin }}$ is minimum power loss value and it is related to the motor speed and load.

According to equations (19) and (28), the system efficiency equation can be expressed as follows: 


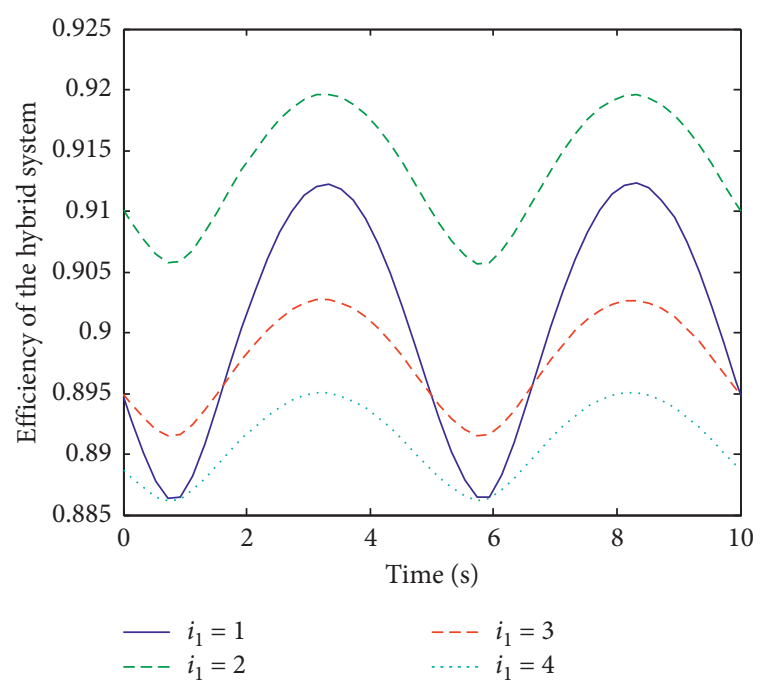

(a)

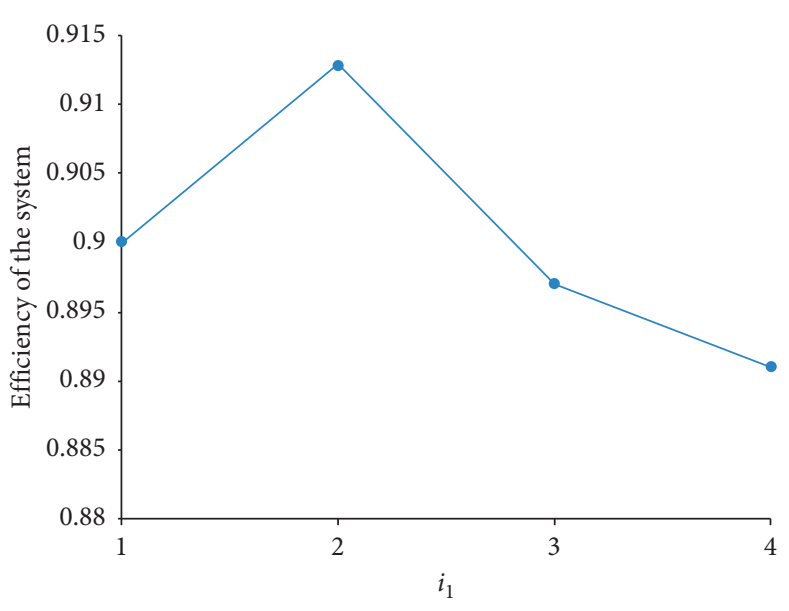

(b)

FIGURE 22: Efficiency curves of the system. (a) Dynamic efficiency curves; (b) scatter points under different transmission ratios.

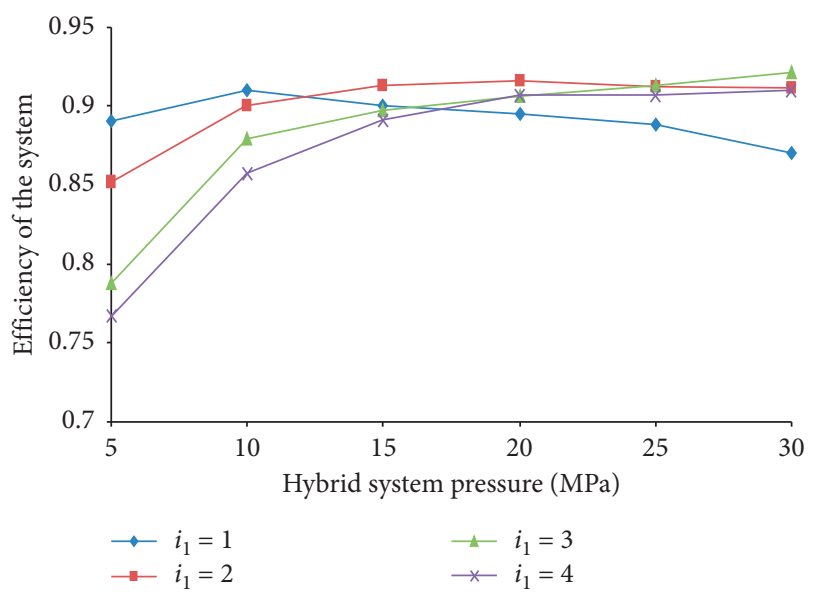

Figure 23: The curve of efficiency with pressure under different transmission ratios.

$$
\eta=1-\frac{P_{\text {loss }}}{P_{\text {loss }}+\left(\bar{T}_{L} / i\right) \cdot n_{e} \cdot(\pi / 30)} .
$$

Therefore, as long as $\bar{p}_{h}$ and $i_{1}$ meet (38), the hybrid system can achieve minimum energy loss and maximum efficiency.

\subsection{Energy-saving Comparison Analysis of Hybrid Power} System. Due to the gearbox has many faults, this paper chooses to omit the reducer and $i_{1}$ is set to 1.0. The best working pressure is $10.25 \mathrm{MPa}$. The maximum efficiency of the hybrid system is 0.921 and the minimum efficiency of the hybrid system is 0.9 when $\beta_{p \text { min }}$ and $\beta_{m \text { min }}$ are set to 0.2 . When the original system applies a $37 \mathrm{~kW}$ electromotor, the average efficiency of the motor is 0.581 . When the hybrid system is adopted, the average efficiency of the motor can be improved to 0.812 . It can be deduced that the rated power of the motor can be reduced by adopting the hydraulic- electromotor hybrid power system. Power saving rate $k$ formula is defined as follows:

$$
k=\frac{W_{\text {original }}-W_{\text {hybrid }}}{W_{\text {original }}},
$$

where $W_{\text {original }}$ is electromotor energy consumption without hybrid power structure, and $W_{\text {hybrid }}$ is electromotor energy consumption with hybrid power structure. By using a hybrid power system, when a $37 \mathrm{~kW}$ electromotor is applied, the power saving rate $k$ is $38.4 \%$. In addition, when the $11 \mathrm{~kW}$ electromotor is applied, the power saving rate $k$ is $44.5 \%$. This comparison result can demonstrate the energy-saving characteristics of the new-type hybrid power structure.

\section{Conclusions}

This paper demonstrates that the system can achieve energy regulation and power hybrid through theoretical simulation and experimental verification, which can eliminate the negative torque phenomenon and improve the power transmission efficiency. The experimental results show that the main factors affecting the efficiency of hydraulic-electromotor hybrid power system are working pressure, coupling speed, and maximum displacement value of pump and hydraulic motor. Through theoretical and experimental research, some conclusions can be obtained.

(1) The displacement ratio of the pump and the hydraulic motor is as small as possible which is conducive to improve hybrid system efficiency and reduce the system cost. Pressure and transmission ratio have a great impact on the hybrid system efficiency, and they have a coupling relationship.

(2) The optimization equation between pressure and transmission ratio is established in this paper. As long as the transmission ratio and pressure can meet the optimization equation, then the system efficiency 
can be the highest. And the maximum efficiency value is only related to the electromotor speed and load.

(3) The energy-saving performance of the hybrid system is analyzed by using the optimal parameter combination. The average efficiency of the motor is $58 \%$ when the motor drives the pumping unit directly. Then, the efficiency of the motor is $81 \%$ when hydraulic-electromotor hybrid power system is added to the transmission chain. Under the optimal parameter combination, the maximum efficiency of the hydraulic-electromotor system is $92 \%$. Therefore, the electric power transmission efficiency can be raised to $75 \%$. The energy transmission efficiency can be improved by $17 \%$ by adopting the hydraulic-electromotor hybrid power system.

\section{Nomenclature}

$D_{p \max }:$ Maximum displacement of pump $\left(\mathrm{m}^{3} / \mathrm{r}\right)$

$D_{\mathrm{p}}: \quad$ Displacement of pump $\left(\mathrm{m}^{3} / \mathrm{r}\right)$

$\beta_{p}$ : $\quad$ Displacement ratio of pump

$\Delta q_{p}: \quad$ Laminar leakage flow of pump $\left(\mathrm{m}^{3} / \mathrm{s}\right)$

$C_{p s}$ : Laminar leakage coefficient of pump.

$P_{\mathrm{h}}$ : $\quad$ Pipeline pressure $(\mathrm{Pa})$

$\mu$ : $\quad$ Dynamic viscosity of hydraulic oil $(\mathrm{Pa} \cdot \mathrm{s})$

$q_{p}: \quad$ Flow of the pump $\left(\mathrm{m}^{3} / \mathrm{s}\right)$

$n_{p}: \quad$ Speed of the pump ( $\left./ \mathrm{min}\right)$

$\Delta T_{\mathrm{p}}: \quad$ Friction loss torque of pump $(\mathrm{N} \cdot \mathrm{m})$

$C_{p v}: \quad$ Laminar drag coefficient of pump

$C_{p f}$ : Mechanical resistance coefficient of pump

$T_{p}$ : $\quad$ Pump drive torque $(\mathrm{N} \cdot \mathrm{m})$

$J_{p}: \quad$ Moment of inertia of pump $\left(\mathrm{kg} \cdot \mathrm{m}^{2}\right)$

$\alpha_{p}: \quad$ Angular acceleration of the pump $\left(\mathrm{rad} / \mathrm{s}^{2}\right)$

$P_{a}: \quad$ Gas pressure of the accumulator $(\mathrm{Pa})$

$r$ : Polytropic coefficient

$n_{L}$ : $\quad$ Crank speed of pumping unit $(\mathrm{r} / \mathrm{min})$

$n_{e}$ : $\quad$ Electromotor rotational speed $(\mathrm{r} / \mathrm{min})$

$i$ : $\quad$ Total transmission of pumping unit

$\Delta T: \quad$ Torque loss of gear transmission $(\mathrm{N} \cdot \mathrm{m})$

$P_{e}: \quad$ Electromotor power $(\mathrm{W})$

$P_{m \text {-loss: }}:$ Power loss of hydraulic motor $(\mathrm{W})$

$\bar{p}_{h}: \quad$ Pipeline average pressure $(\mathrm{Pa})$

$D_{m \text { min }}$ : Minimum displacement of hydraulic motor $\left(\mathrm{m}^{3} / \mathrm{r}\right)$

$T_{L \text { min }}$ : Toque minimum value of the crank shaft $(\mathrm{N} \cdot \mathrm{m})$

$\beta_{m \text { min }}$ : Minimum displacement ratio of hydraulic motor

$\triangle T_{\text {min }}:$ Minimum torque difference $(\mathrm{N} \cdot \mathrm{m})$

$D_{\text {mmax }}$ : Maximum displacement of hydraulic motor $\left(\mathrm{m}^{3} / \mathrm{r}\right)$

$D_{m}: \quad$ Displacement of hydraulic motor $\left(\mathrm{m}^{3} / \mathrm{r}\right)$

$\beta_{m}$ : $\quad$ Displacement ratio of hydraulic motor

$\Delta q_{m}: \quad$ Laminar leakage flow of hydraulic motor $\left(\mathrm{m}^{3} / \mathrm{s}\right)$

$C_{\mathrm{ms}}$ : Laminar flow leakage coefficient of hydraulic motor

$q_{m}$ : $\quad$ Flow of the hydraulic motor $\left(\mathrm{m}^{3} / \mathrm{s}\right)$

$n_{m}$ : Speed of the hydraulic motor $(\mathrm{r} / \mathrm{min})$

$\Delta T_{m}: \quad$ Friction loss torque $(\mathrm{N} \cdot \mathrm{m})$

$C_{m v}: \quad$ Laminar drag coefficient of hydraulic motor

$C_{m f}$ : Mechanical resistance coefficient of hydraulic motor

$T_{m}: \quad$ Hydraulic motor output torque $(\mathrm{N} \cdot \mathrm{m})$
$J_{m}: \quad$ Moment of inertia of the hydraulic motor $\left(\mathrm{kg} \cdot \mathrm{m}^{2}\right)$

$\alpha_{m}$ : Angular acceleration of the hydraulic motor $\left(\mathrm{rad} / \mathrm{s}^{2}\right)$

$P_{0}: \quad$ Inflation pressure of the accumulator $(\mathrm{Pa})$

$V_{0}: \quad$ Initial volume of accumulator $\left(\mathrm{m}^{3}\right)$

$V_{a}: \quad$ Gas volume when gas pressure is $P_{a}\left(\mathrm{~m}^{3}\right)$

$q_{a}: \quad$ Low of the accumulator $\left(\mathrm{m}^{3} / \mathrm{s}\right)$

$T_{L}$ : Crank torque of pumping unit $(\mathrm{N} \cdot \mathrm{m})$

$T_{e}: \quad$ Electromotor torque $(\mathrm{N} \cdot \mathrm{m})$

$i_{1}$ : $\quad$ Reducer (2) transmission ratio

$\eta$ : $\quad$ Hybrid system efficiency

$P_{p^{-} \text {loss }}:$ power loss of pump (W)

$T_{L}$ : Average toque of the crank shaft $(\mathrm{N} \cdot \mathrm{m})$

$D_{p \text { min }}$ : Minimum displacement of pump $\left(\mathrm{m}^{3} / \mathrm{r}\right)$

$T_{L \text { max }}$ : Toque maximum value of the crank shaft $(\mathrm{N} \cdot \mathrm{m})$

$\beta_{p \text { min }}$ : Minimum displacement ratio of pump

$\triangle T_{\text {max }}:$ Maximum torque difference $(\mathrm{N} \cdot \mathrm{m})$

$P_{\text {loss }}: \quad$ Power loss of the hybrid system (W).

\section{Data Availability}

All data included in this study are available upon request by contact with the corresponding author.

\section{Conflicts of Interest}

The authors declare that they have no conflicts of interest.

\section{Acknowledgments}

This research was funded by the Science Research Foundation of Inner Mongolia University for the nationalities (grant no. NMDGP1704), the National Nature Science Foundation of China (grant no. 51865046), Science and Technology Innovation Leading Project of Inner Mongolia (grant no. KCBJ2018028), and Program for Young Talents of Science and Technology in Universities of Inner Mongolia Autonomous Region (grant no. NJYT-19-B150).

\section{References}

[1] P. Xu, S. Xu, and H. Yin, "Application of self-organizing competitive neural network in fault diagnosis of suck rod pumping system," Journal of Petroleum Science and Engineering, vol. 58, no. 1-2, pp. 43-45, 2007.

[2] H. Meng, L. Quan, Z. Wang et al., "An energy-saving pumping system with novel springs energy storage devices: design, modeling, and experiment," Advances in Mechanical Engineering, vol. 9, no. 1, Article ID 168781401668745, 2017.

[3] K. Li, Y. Han, and T. Wang, "A novel prediction method for down-hole working conditions of the beam pumping unit based on 8-directions chain codes and online sequential extreme learning machine," Journal of Petroleum Science and Engineering, vol. 160, pp. 285-301, 2018.

[4] W. Luo, B. Wang, H. Zhao et al., "Modeling and simulation of non-linear dynamic process of the induction motor system with fluctuating potential loads," Science China Technological Sciences, vol. 57, no. 9, pp. 1729-1737, 2014.

[5] J. Lu, J. He, C. Mao, W. Wu, D. Wang, and W.-J. Lee, “Design and implementation of a dual pwm frequency converter used 
in beam pumping unit for energy saving," IEEE Transactions on Industry Applications, vol. 50, no. 5, pp. 2948-2956, 2014.

[6] Z. Feng, X. Fang, and H.-H. Ding, "Study ON working performance OF phased beam pumping unit," Journal of the Balkan Tribological Association, vol. 22, no. 1, pp. 104-111, 2016.

[7] H. Fu, L. Zou, Y. Wang, Z. Feng, and Z. Song, "Study on design and simulation analysis of the double horse-head pumping unit based on the compound balance structure," Proceedings of the Institution of Mechanical Engineers, Part C: Journal of Mechanical Engineering Science, vol. 229, no. 16, pp. 3034-3046, 2015.

[8] Z.-M. Feng, J.-J. Tan, X. Liu, and X. Fang, "Selection method modelling and matching rule for rated power of prime motor used by beam pumping units," Journal of Petroleum Science and Engineering, vol. 153, pp. 197-202, 2017.

[9] Z. Haisen, W. Yilong, Y. Zhan, G. Xu, X. Cui, and J. Wang, "Practical model for energy consumption analysis of beam pumping motor systems and its energy saving applications," in Proceedings of the IEEE Transactions on Industry Applications, pp. 1-9, Cincinnati, OH, USA, October 2017.

[10] Z. Feng, J. Tan, Y. Sun, D. Zhang, and W. Duan, "3D-Dynamic modelling and performance analysis of service behavior for beam pumping unit," Mathematical Problems in Engineering, vol. 2018, no. 7, Article ID 9205251, 2018.

[11] L. Yingli, C. Xueshen, Z. Haisen, Z. Deqing, L. Yu, and W. Yilong, "A multifunction energy-saving device with a novel power-off control strategy for beam pumping motors," IEEE Transactions on Industry Applications, vol. 47, no. 4, pp. 1605-1611, 2011.

[12] H. Zhao, Y. Wang, G. Chen, Y. Zhan, and G. Xu, "Precise determination of power-off time of intermittent supply technology based on fuzzy control for energy saving of beam pumping motor systems," Electric Power Components and Systems, vol. 46, no. 2, pp. 197-207, 2018.

[13] M. Z. Northimi, M. Hamdi, S. Nurmaya Musa, L. H. Saw, N. A. Mardi, and N. Hilman, "Load and stress analysis for the swash plate of an axial piston pump/motor," Journal of $D y$ namic Systems Measurement and Control-Transactions, vol. 133, no. 6, 2011.

[14] Z.-L. Zhang and J. Chen, "Implementable strategy research of brake energy recovery based on dynamic programming algorithm for a parallel hydraulic hybrid bus," International Journal of Automation and Computing, vol. 11, no. 3, pp. 249-255, 2014.

[15] X. Ning, J. Shangguan, Y. Xiao et al., "Optimization of energy recovery efficiency for parallel hydraulic hybrid power systems based on dynamic programming," Mathematical Problems in Engineering, vol. 2019, Article ID 9691507, 11 pages, 2019.

[16] Y. Chen, X. Liu, X. Wang, and J. Chen, "Simulation and data analysis of energy recovery sensing on parallel hydraulic hybrid crane," Intelligent Automation and Soft Computing, vol. 24, no. 3, pp. 613-623, 2018.

[17] Y. Liang, T. Wang, X. Wang, W. Liang, and X. Liu, "Simulation research on hydraulic hybrid assistant beam pumping unit," Proceedings of the Institution of Mechanical Engineers, Part C: Journal of Mechanical Engineering Science, vol. 230, no. 11, pp. 1795-1804, 2016.

[18] H. Deng, Q. Wang, D. Peng, and Y. Yang, "Study on leaking characteristics of port plate pair in primary three-row axial piston pump/motor," Mathematical Problems in Engineering, vol. 2018, Article ID 7395727, 9 pages, 2018.
[19] Y. Liu, X. Gao, and Z. Pei, "Research of impact load in large electrohydraulic load simulator," Mathematical Problems in Engineering, vol. 2014, Article ID 821419, 7 pages, 2014.

[20] Y. Liu, X. Gao, and X. Yang, "Research of control strategy in the large electric cylinder position servo system," Mathematical Problems in Engineering, vol. 2015, Article ID 167628, 6 pages, 2015.

[21] C. Zhang, L. Wang, and H. Li, "Experiments and simulation on a late-model wind-motor hybrid pumping unit," Energies, vol. 13, no. 4, p. 994, 2020.

[22] N. T. Hoang and H. S. Yan, "Configuration synthesis of novel series-parallel hybrid transmission systems with eight-bar mechanisms," Energies, vol. 10, no. 7, p. 1044, 2017.

[23] N. T. Hoang and H. S. Yan, "Configuration synthesis of novel series-parallel hybrid transmission systems with eight-link ravigneaux mechanisms," Journal of the Chinese Society of Mechanical Engineers, vol. 39, no. 4, pp. 345-355, 2018.

[24] N.-T. Hoang and H.-S. Yan, "On the innovation design for two-motor transmissions with eight-link mechanisms in the electric vehicles," Applied Sciences, vol. 9, no. 1, p. 140, 2019. 